\title{
Learning Enhances Sensory Processing in Mouse V1 before Improving Behavior
}

\author{
Ovidiu Jurjut, ${ }^{1}$ ○Petya Georgieva, ${ }^{1}$ Laura Busse, ${ }^{1,2}$ and $\odot$ Steffen Katzner $^{1,2}$ \\ ${ }^{1}$ Werner Reichardt Centre for Integrative Neuroscience, University of Tübingen, Tübingen 72076, Germany, and ${ }^{2}$ Division of Neurobiology, Department \\ Biology II, LMU Munich, Munich 82151, Germany
}

\begin{abstract}
A fundamental property of visual cortex is to enhance the representation of those stimuli that are relevant for behavior, but it remains poorly understood how such enhanced representations arise during learning. Using classical conditioning in adult mice of either sex, we show that orientation discrimination is learned in a sequence of distinct behavioral stages, in which animals first rely on stimulus appearance before exploiting its orientation to guide behavior. After confirming that orientation discrimination under classical conditioning requires primary visual cortex $(\mathrm{V} 1)$, we measured, during learning, response properties of $\mathrm{V} 1$ neurons. Learning improved neural discriminability, sharpened orientation tuning, and led to higher contrast sensitivity. Remarkably, these learning-related improvements in the V1 representation were fully expressed before successful orientation discrimination was evident in the animals' behavior. We propose that $\mathrm{V} 1$ plays a key role early in discrimination learning to enhance behaviorally relevant sensory information.
\end{abstract}

Key words: behavior; discrimination learning; mouse vision; primary visual cortex

\section{Significance Statement}

Decades of research have documented that responses of neurons in visual cortex can reflect the behavioral relevance of visual information. The behavioral relevance of any stimulus needs to be learned, though, and little is known how visual sensory processing changes, as the significance of a stimulus becomes clear. Here, we trained mice to discriminate two visual stimuli, precisely quantified when learning happened, and measured, during learning, the neural representation of these stimuli in V1. We observed learning-related improvements in V1 processing, which were fully expressed before discrimination was evident in the animals' behavior. These findings indicate that sensory and behavioral improvements can follow different time courses and point toward a key role of $\mathrm{V} 1$ at early stages in discrimination learning.

\section{Introduction}

How does sensory processing in visual cortex change during learning of a stimulus' behavioral relevance? A fundamental property of neurons in visual cortex is to enhance the representation of those stimuli that are relevant for behavior (for review, see Gilbert and Li, 2013; Gavornik and Bear, 2014; Maunsell, 2015). The behavioral relevance of any given stimulus needs to be learned, though, and little is known about how visual sensory processing changes, as the significance of that stimulus becomes clear. Although long-lasting alterations in visual cortical process-

\footnotetext{
Received Nov. 10, 2016; revised April 28, 2017; accepted May 20, 2017.

Author contributions: L.B. and S.K. designed research; 0.J. and P.G. performed research; 0.J., L.B., and S.K. analyzed data; L.B. and S.K. wrote the paper.

This work was supported by European Research Council Starting Independent Researcher Grant 281885 PERCEPT to S.K. and by funds awarded to the Centre for Integrative Neuroscience within the framework of German Excellence Initiative DFG EXC 307. We thank Daniel Fürth for valuable advice; and Dimitri Yatsenko and Alexander Ecker for sharing code for data management (DataJoint, http://datajoint.github.io/).

The authors declare no competing financial interests.

Correspondence should be addressed to Dr. Steffen Katzner, LMU Munich, Division of Neurobiology, Department Biology II, Grosshadernerstr. 2, 82152 Planegg-Martinsried, Germany. E-mail: steffen.katzner@Imu.de.

DOI:10.1523/JNEUROSCI.3485-16.2017

Copyright $\odot 2017$ the authors $\quad 0270-6474 / 17 / 376460-15 \$ 15.00 / 0$
}

ing after mere exposure to specific stimuli (Frenkel et al., 2006; Cooke and Bear, 2010; Cooke et al., 2015) or after learning (Crist et al., 2001; Schoups et al., 2001; Ghose et al., 2002; Schwartz et al., 2002; Furmanski et al., 2004; Li et al., 2004; Yang and Maunsell, 2004; Raiguel et al., 2006; Hua et al., 2010; Jehee et al., 2012; Goltstein et al., 2013) have been documented amply, demonstrations of dynamic changes during learning are rare (Law and Gold, 2008; Li et al., 2008; Poort et al., 2015).

How animals learn about the relevance of any stimulus has been extensively studied at the level of behavior, where much of the research has relied on classical conditioning. Classical conditioning has the advantage that the occurrence of each lesson, such as a pairing of a stimulus with a reward, is entirely under the experimenter's, and not the animal's, control (Pearce and Bouton, 2001). Therefore, the speed of learning can be elegantly manipulated, and its time course precisely quantified (Balsam and Gallistel, 2009).

Classical conditioning is often viewed as a reflexive, automatic type of learning; it does, however, involve substantial cognitive processes related to attention and decision-making. Support for these processes comes from the analysis of single-subject learning curves, which reveal in many learning paradigms step-like changes 
in behavior. Such step-like changes are inconsistent with a gradual strengthening of an association (Rescorla and Wagner, 1972) but can readily be explained within the framework of perceptual decision making (Gallistel and Gibbon, 2000): across trials, the animal accumulates evidence that a given stimulus reliably predicts an important event and decides to show the conditioned response once the evidence is strong enough. The implication of these findings is that learning curves of individual subjects can be decomposed into a sequence of well-defined stages.

Whether progress in behavior and changes in sensory processing occur in parallel, or follow different time courses, is a matter of debate. Changes in sensory processing have been extensively investigated in primate studies of perceptual learning (for review, see Gilbert and Li, 2012). In those rare cases where neural activity was measured during task performance, improvements in behavioral sensitivity were largely paralleled by improvements in neural representations (Law and Gold, 2008; Li et al., 2008). Similar observations were recently made in mouse $\mathrm{V} 1$, where chronic 2-photon calcium imaging revealed changes in population selectivity in parallel with progress in discrimination learning (Poort et al., 2015). Other studies, however, have documented that learning-related changes in neural processing can be dissociated in time from behavioral effects. In those cases, learning-related changes in neural activity are rather transient; they are pronounced during initial phases of training but relax, with additional practice, to pretraining levels, although behavioral performance remains high (Zelcer et al., 2006; Yotsumoto et al., 2008; Sarro et al., 2015).

Here, we exploited the advantages of classical conditioning and quantified, in individual mice, the time course of orientation discrimination learning. Learning indeed occurred in a sequence of distinct stages, which were marked by qualitative changes in behavior. During traversal of these stages, we measured response properties of V1 neurons and found that the neural representation of the stimuli was improved to full extent well before animals showed any behavioral sign of orientation discrimination. These neural signatures likely reflect a key role of V1, which might enhance, early in discrimination learning, behaviorally relevant visual information.

\section{Materials and Methods}

We used 16 mice (2-6 months old, 11 males and 5 females): 13 of the C57BL/6J wild-type strain and 3 of the PV-Cre strain B6;129P2Pvalbtm1 (cre)Arbr/J (JAX stock \#008069). All procedures were performed in compliance with the European Communities Council Directive 2010/63/ EC and the German Law for Protection of Animals; they were approved by the local authorities following appropriate ethics review.

Surgical protocol. Anesthesia was induced with isoflurane $(3 \%)$ and maintained throughout the surgery (1.5\%). A custom lightweight aluminum headpost was attached to the anterior part of the skull (OptiBond FL primer and adhesive, Kerr Dental; Tetric EvoFlow dental cement, Ivoclar Vivadent); two miniature screws $(00-96 \times 1 / 16$ stainless steel screws, Bilaney) were implanted over the cerebellum serving as reference and ground for electrophysiological recordings. Before surgery, atropine (Atropinsulfat B. Braun, $0.3 \mathrm{mg} / \mathrm{kg} \mathrm{sc}$ ) and analgesics (buprenorphine, 0.1 $\mathrm{mg} / \mathrm{kg} \mathrm{sc}$ ) were administered, and eyes were protected with ointment (Bepanthen). The animal's temperature was kept at $37^{\circ} \mathrm{C}$ via a feedbackcontrolled heating pad (WPI). Antibiotics (Baytril, $5 \mathrm{mg} / \mathrm{kg} \mathrm{sc}$ ) and a longer-lasting analgesic (carprofen, $5 \mathrm{mg} / \mathrm{kg} \mathrm{sc}$ ) were administered for $3 \mathrm{~d}$ after surgery. Expression of channelrhodopsin (ChR2) in PV-Cre mice was achieved by injecting into V1 of anesthetized animals, through a small craniotomy, the adeno-associated viral vector rAAV5.EF1a.DIO. hChR2(H134R)-EYFP.WPRE.hGH (Penn Vector Core, University of Pennsylvania). A Picospritzer III (Parker) was used to inject the virus at multiple depths while gradually retracting the pipette. Mice were given $7 \mathrm{~d}$ to recover before they were habituated to the experimental setup.
Before electrophysiological recordings, a craniotomy $\left(\sim 1.5 \mathrm{~mm}^{2}\right)$ was performed over $\mathrm{V} 1,3 \mathrm{~mm}$ lateral to the midline and $1.1 \mathrm{~mm}$ anterior to the transverse sinus (Wang et al., 2011). The craniotomy was sealed with Kwik-Cast (WPI), which was removed and reapplied before and after each recording session.

Experimental setup and visual stimulation. Mice were put on an aircushioned Styrofoam ball and head-fixed by clamping their headpost to a rod. Movements of the ball were recorded at $90 \mathrm{~Hz}$ by 2 optical mice connected to a microcontroller (Arduino Duemilanove). A computercontrolled syringe pump (Aladdin AL-1000, WPI) delivered precise amounts of water through a drinking spout, which was positioned in front of the animals' snout. Attached to the spout was a piezo element, which registered licking behavior (Schwarz et al., 2010). The drinking spout was present only during the conditioning experiments and removed during measurements of orientation tuning. Visual stimuli were generated with custom-written software (https://sites.google.com/a/nyu. edu/expo/home) and presented on a liquid crystal display monitor $25 \mathrm{~cm}$ in front of the animals' eyes (Samsung 2233RZ, mean luminance of $50 \mathrm{~cd} / \mathrm{m}^{2}$, refresh rate $120 \mathrm{~Hz}$ ). Luminance nonlinearities of the display were corrected with an inverse gamma lookup table, which was regularly obtained by calibration with a photometer. Stimuli consisted of sinusoidal or square wave gratings, which were $40-50$ degrees in diameter, and positioned to maximally overlap with the receptive fields (RFs) of the recorded neurons. Temporal frequency was $1.5 \mathrm{~Hz}$; spatial frequency was 0.02-0.04 cycles/degree. The setup was enclosed with a black fabric curtain. Eye movements were monitored under infrared illumination using a zoom lens (Navitar Zoom 6000) coupled to a camera (Guppy AVT, frame rate $50 \mathrm{~Hz}$ ). Optical stimulation was delivered via an optical fiber coupled to a light-emitting diode (LED; Doric Lenses) with a center wavelength of $473 \mathrm{~nm}$, which was driven by an LED driver (LEDD1B, Thorlabs). The fiber core was $910 \mu \mathrm{m}$ in diameter, and the LED light intensity, measured at the tip of the fiber, was $0.7-3.5 \mathrm{~mW} / \mathrm{mm}^{2}$. Before every recording session, the fiber was positioned over the craniotomy, perpendicular to the brain surface, at a distance of $\sim 1 \mathrm{~mm}$ using a micromanipulator. The animal's eyes were shielded from the blue light by a sheet of black nonreflecting aluminum foil placed around the stimulation site.

Initial behavioral training. After recovery from the surgery, animals were placed on a water restriction schedule until their weight dropped below $85 \%$ of their ad libitum body weight. During this time, mice were habituated to head fixation on the ball and delivery of water through the spout, which was triggered by the animal's licking in the absence of visual stimuli. The animals' weight and fluid consumption were monitored and recorded on each day, and the animals were checked for potential signs of dehydration. After the weight had stabilized, the classical conditioning sessions started. These were typically performed $7 \mathrm{~d}$ a week, and only during these sessions did mice receive water.

Conditioning paradigm. Animals were trained to discriminate between two gratings: one of them drifting down and to the left ( 315 degrees) and the other one down and to the right (45 degrees). We chose these two directions because they provide comparable sensory drive to neurons preferring horizontal gratings (i.e., 0 or 180 degrees), which are prominent in mouse V1 (Kreile et al., 2011). Gratings could vary in contrast (6 levels: $1,2,4,6,16,40$, and 100\%). On a given trial, contrast and direction of movement were determined pseudo-randomly, and the grating was presented for $3 \mathrm{~s}$. The presentation of one grating was always followed by reward delivery $(2-7 \mu \mathrm{l})$; the other grating had no consequences. The grating at 315 degrees was the rewarded stimulus for all but one animal; for this one animal, the other stimulus was rewarded. The intertrial interval was $8-15$ s plus a random delay drawn from an exponential distribution with a mean of $10-15 \mathrm{~s}$. With such an interval, the animals cannot predict the onset of the stimulus. A single session consisted of 120-240 trials per day, divided into blocks of 60 trials.

Electrophysiological recordings. Extracellular recordings were performed with 32-channel linear silicon probes (Neuronexus, A1x32-5 $\mathrm{mm}-25-177-\mathrm{A} 32)$. Electrodes were inserted perpendicular to the brain surface and lowered to $\sim 900 \mu \mathrm{m}$ below the surface. Wideband extracellular signals were digitized at $30 \mathrm{kHz}$ (Blackrock Microsystems) and analyzed using the NDManager software suite (Hazan et al., 2006). Local field potentials (LFPs) were extracted by downsampling $(1250 \mathrm{~Hz})$ and 
filtering (4-250 $\mathrm{Hz}$ bandpass) the wideband signal. To isolate single neurons from linear arrays, we grouped adjacent channels into five equally sized "virtual octrodes" (eight channels per group with two channel overlap). Using an automatic spike detection threshold (Quiroga et al., 2004), spikes were extracted from the high-pass filtered continuous signal for each group separately. The first three principal components of each channel were used for automatic clustering with KlustaKwik (K. D. Harris, http://klusta-team.github.io/klustakwik), which was followed by manual refinement of clusters (Hazan et al., 2006). In the analyses of neural data, we only considered high-quality single-unit activity, judged by the distinctiveness of the spike wave shape and cleanness of the refractory period in the autocorrelogram.

Measurements of eye position. The details are described by Erisken et al. (2014). Briefly, we detected the pupil by convolving acquired camera frames with a symmetric Gaussian filter and applied a user-defined threshold to obtain a binary image. We then applied a morphological opening operation, identified the most circle-like object as the pupil, and fitted an ellipse to determine the position of its center. To identify and compensate for translations of the eye parallel to the image plane, we also determined the position of a landmark, which could be either the first Purkinje image of the infrared light or a user-defined point near the tear duct in the medial corner of the eye (Wallace et al., 2013). We computed relative pupil displacements by subtracting, for each frame, the landmark position from the pupil position. To convert pupil displacements to angular displacements, we assumed that the center of eye rotation was $1.041 \mathrm{~mm}$ behind the pupil (Stahl et al., 2000). We defined saccades as changes in eye position $>2$ degrees. Considering that the average mouse saccade lasts $\sim 50 \mathrm{~ms}$ (Sakatani and Isa, 2007), we detected saccades by taking the difference of mean eye position $60 \mathrm{~ms}$ before and after each time point.

Measurements of response properties. Before each classical conditioning experiment, we mapped RF properties and measured orientation tuning. (1) RFs were mapped with a sparse noise stimulus, consisting of 5 degree full-contrast black and white squares, which were flashed, on a gray background, for $150 \mathrm{~ms}$ at a random location in a virtual $12 \times 12$ grid. Responses were fitted with a 2D ellipse to determine RF center, separately for ON and OFF subfields (Liu et al., 2010). (2) Orientation tuning was measured by presenting sinusoidal gratings at $100 \%$ contrast moving in a randomly selected direction (12 levels) for a duration of $2 \mathrm{~s}$. Intertrial interval was $0.5 \mathrm{~s}$. A blank screen condition (mean luminance) was included to estimate spontaneous firing rate. Each direction was presented 20 times. Orientation tuning curves were fit with a sum of two Gaussians, whose peaks were separated by 180 degrees as follows:

$$
R(\theta)=R_{0}+R_{p} \mathrm{e}^{-\frac{\left(\theta-\theta_{p}\right)^{2}}{2 \sigma^{2}}}+R_{n} \mathrm{e}^{-\frac{\left(\theta-\theta_{\mathrm{p}}+180\right)^{2}}{2 \sigma^{2}}}
$$

The function has five parameters: preferred orientation $\theta_{p}$, tuning width $\sigma$, baseline response $R_{0}$, response at the preferred orientation $R_{p}$, and response at the null orientation $R_{n}$. We determined a direction selectivity index, as the difference in mean firing rates between opposite directions, divided by their sum, and collapsed across opposite motion directions unless a neuron was selective for direction (direction selectivity index $>0.2$ ). To combine data from animals with different stimulus-reward assignments, we expressed a neuron's preferred orientation relative to the rewarded orientation.

Contrast sensitivity was measured during the classical conditioning experiments, in which rewarded and unrewarded stimuli were presented at a range of contrasts. Contrast responses were fitted with the hyperbolic ratio function (Albrecht and Hamilton, 1982) as follows:

$$
R(c)=R_{0}+R_{\max } \frac{c^{n}}{c_{50}^{n}+c^{n}}
$$

where $c$ is stimulus contrast. The function has four parameters: baseline response $R_{0}$, maximum response $R_{\max }$, semisaturation contrast $c_{50}$, and exponent $n$. In a substantial fraction of V1 neurons, responses did not saturate with increasing stimulus contrast. In these cases, estimates of $c_{50}$ hit the upper bound of meaningful values (i.e., 100\%). To avoid this limitation, we took as a measure of contrast sensitivity the contrast, at which the neural response reached half of the maximum amplitude.
Current source density (CSD) analysis. We computed the CSD from the second spatial derivative of the LFP (Mitzdorf, 1985) in response to periodic visual stimulation. We smoothed the CSD in space using a triangular kernel (Nicholson and Freeman, 1975) and used a value of $0.4 \mathrm{~S} / \mathrm{m}$ as measure of cortical conductivity (Logothetis et al., 2007) to approximate the CSD in units of nanoamperes per cubic millimeter. We assigned the contact closest to the earliest polarity inversion to the base of layer 4 (Schroeder et al., 1998). The remaining contacts were assigned to putative supragranular, granular, and infragranular layers based on a cortical thickness of $1 \mathrm{~mm}$ and anatomical measurements of the relative thickness of individual layers in mouse V1 (Heumann et al., 1977).

Analysis of visually evoked potentials (VEPs). VEPs were analyzed by computing the stimulus-triggered average from bandpass filtered (3-90 $\mathrm{Hz}$ ) LFPs recorded in layer 4 during measurements of orientation tuning. VEP amplitude was quantified by measuring trough-to-peak amplitude (Frenkel and Bear, 2004), where the trough was defined as the minimum value in the time interval from 0 to $100 \mathrm{~ms}$ after stimulus onset and the peak as the maximum value from 50 to $200 \mathrm{~ms}$.

\section{Analysis of behavior}

We quantified licking behavior on each trial by an index (lick index [LI]) as follows:

$$
L I=\left(\text { licks }_{\text {stimulus }}-l i c k s_{\text {baseline }}\right) /\left(\text { licks }_{\text {stimulus }}+l i c k s_{\text {baseline }}\right),
$$

where licks stimulus is the number of licks during the final $1 \mathrm{~s}$ of stimulus presentation and licks baseline is the number of licks during the final $1 \mathrm{~s}$ before stimulus presentation. This index is bound between -1 and 1 , with the two extremes indicating that licks exclusively occur during the baseline period or during grating presentation. We assessed learning progress by analyzing the cumulative sum of LIs (Papachristos and Gallistel, 2006), where changes in behavior become evident as changes in slope. Slope changes in the cumulative sum can more easily be seen than changes in raw indices across trials (Gallistel et al., 2004), and cumulative sums for all three learning stages can be compared in a single panel. To detect significant changes in slope, we performed the change the point analysis described by Gallistel et al. (2001). To identify the transition from the naive to the intermediate stage, we examined LIs for the rewarded stimulus and determined the trial at which the first change point occurred. To identify the transition from the intermediate to the trained stage, we performed the same analysis on the difference between the cumulative LIs for the rewarded and the unrewarded stimulus. To quantify the number of slope changes, we counted how many change points were needed before a postchange slope reached $80 \%$ of the terminal slope, which was based on the final half of the trials. For all but one analysis (28 of 29), we used a statistical criterion of $p<10^{-6}$ for accepting changes in slope. In the remaining case, we lowered this criterion to $p<10^{-5}$. To validate the placement of change points, we performed ideal observer analyses (Macmillan and Creelman, 2005). For the first transition, we compared the distribution of lick rates compiled from the final second before stimulus onset against the distribution compiled from the final second during stimulus presentation. For this analysis, we only used trials in which the rewarded stimulus was shown and compared classification performance in the naive versus later stages (i.e., intermediate and trained). For the second transition, we compiled distributions of LIs for rewarded versus unrewarded trials and compared classification performance in the trained versus earlier stages (i.e., naive and intermediate).

Animals were considered nonlearners if their licking behavior failed to show a transition to the trained stage within 2000 trials. Three animals, however, did not receive the full amount of training because decreasing quality of neural recordings led us to terminate learning sessions. In detail, of the 16 mice we used, 1 dropped out before reaching the intermediate stage; 15 mice reached the intermediate stage and received further training. Of these 15 animals, 2 more dropped out by terminating learning sessions; 3 mice failed to reach the trained stage and were therefore classified as nonlearners (see Fig. 2I, n/a).

To analyze running behavior, we transformed single-trial speed profiles within each session into binary vectors, in which ones marked time points where the animal was running (speed $>1 \mathrm{~cm} / \mathrm{s}$ ) and zeroes those where the animal was sitting (speed $<1 \mathrm{~cm} / \mathrm{s}$ ). Across trials, we computed, 
for every point in time, the percentage of trials in which the animal was running, before averaging across sessions. To assess statistical significance, we computed, for each session, the average percentage of run trials within 0.1-1.5 s after stimulus onset, separately for each stimulus condition and learning stage. We then performed a mixed-design ANOVA involving the between-subjects factor learning stage (naive vs intermediate vs trained) and the within-subject factor stimulus (rewarded vs unrewarded).

Optogenetic suppression of $V 1$ responses. After the animals had reached the trained stage, in which they could discriminate the two orientations, we combined electrophysiological recordings with photo-stimulation of parvalbumin-expressing $\left(\mathrm{PV}^{+}\right)$interneurons. In a random subset of trials $(33 \%)$, we applied photo-stimulation concurrently with the presentation of the visual stimulus. In the experiments with optogenetic suppression, we only used two levels of stimulus contrast ( $6 \%$ and $40 \%$ ).

\section{Analysis of neural data}

Individual animals typically contributed neural data to single learning stages.

In the analyses of neural discriminability and orientation selectivity, we included neurons if (1) the sum of Gaussians explained $>50 \%$ of the variance in responses, and (2) their mean firing rate across stimulus orientations was at least 1 spike/s.

The time courses of neural activity in Figure $5 A, B$ are spike density functions computed by convolving single-trial spike trains with a Gaussian kernel (kernel resolution $10 \mathrm{~ms}$, kernel width $100 \mathrm{~ms}$ ) before averaging across trials.

Neural discriminability. We quantified how well individual neurons can discriminate the rewarded and unrewarded stimulus by extracting single-trial firing rates in a time window from 0.1 to $1.5 \mathrm{~s}$ after stimulus onset (excluding the transient part of the response) to compute a neural $d^{\prime}$, defined as the difference in mean response to each stimulus, divided by the pooled SD. During this window, mean lick rates were largely similar between stimuli across learning stages (rewarded vs unrewarded stimulus; naive stage: $p=0.97$; intermediate stage: $p=0.43$; trained stage: $p=0.07$; interaction between rewarded vs unrewarded stimulus and learning stage: $p=0.36$, ANOVA). We sorted neurons according to their relative preferred orientation into 4 bins centered on $-135,-90$, -45 , and 0 degrees, and performed an ANOVA on mean $d^{\prime}$ using the between-subject factors learning stage (naive vs intermediate vs trained), layer (L2/L3 vs L4 vs L5/L6), and orientation bin. For post hoc comparisons of individual means, we used Tukey's HSD test, with a $95 \%$ family-wise confidence level to correct for multiple testing. Because learning-related changes in $d^{\prime}$ seemed to be more pronounced for neurons with sharper selectivity, we excluded for this analysis neurons with broad orientation tuning ( $\sigma>40$ degrees). Our results, however, were very similar if these neurons were included.

Orientation selectivity. To compare counts of neurons across orientation bins and learning stages, we performed a log-linear analysis of this multidimensional contingency table. To model the observed counts, we fitted a GLM with a Poisson link function considering the factors orientation bin ( 4 levels) and learning stage (3 levels). To compare the distributions of relative preferred orientations across learning stages without binning (see Fig. $5 F$ ), we used the multisample variant of the nonparametric Anderson-Darling test (Scholz and Stephens, 1987). This is an omnibus test (i.e., it provides a single test statistic to assess whether multiple distributions differ from each other). As an alternative, we compared pairs of distributions using the nonparametric Kolmogorov-Smirnov test, which led to the same conclusion of no difference between learning stages ( $p$ values of $0.70,0.25$, and 0.13 ). To visualize how the laminar profile of tuning width $\sigma$ was affected by learning (Fig. $5 H$ ), we performed a nonparametric, locally weighted, robust polynomial regression (lowess) (Cleveland, 1979), using a parameter value of $=0.3$ for the span of the smoothing window. To assess statistical significance, we ran an ANOVA on $\sigma$, using the same design as for $d^{\prime}$ (see Neural discriminability).

Contrast sensitivity. In the analysis of contrast sensitivity, we included neurons if (1) the hyperbolic ration function explained $>70 \%$ of the variance in contrast responses, and (2) the difference between baseline and maximum response was at least 1 spikes/s. Because contrast sensitivity is bound between 0 and 100 , we assessed statistical significance of learning effects with the nonparametric Kruskal-Wallis omnibus test, followed by pairwise comparisons using the nonparametric MannWhitney test. Performing a standard ANOVA on log-transformed data led to identical conclusions.

To assess whether locomotion affected contrast responses, we analyzed data from a separate batch of animals, unrelated to the current study. For each neuron, we selected trials where the animals ran at least $80 \%$ and at most $20 \%$ of the time to compute contrast responses for locomotion and stationary periods. After fitting contrast responses with hyperbolic ratio functions (Albrecht and Hamilton, 1982), we compared the maximum response and the contrast at half the maximum response for locomotion versus stationary periods using paired $t$ tests.

Lick-triggered analysis of firing rates. We computed perievent spike histograms centered on licks during a time window from 0.1 to $1.5 \mathrm{~s}$ after stimulus onset. We excluded from the analyses experiments with $<10$ licks and neurons with an average firing rate $<1 \mathrm{~Hz}$ in a $200 \mathrm{~ms}$ time interval centered around lick events. To compare distributions of lick-modulation indices across learning stages, we used the multisample variant of the nonparametric Anderson-Darling test (see Orientation selectivity).

\section{Results}

\section{Orientation discrimination learning unfolds as a sequence of distinct stages}

We trained 16 mice, using classical conditioning, to discriminate the orientation of a grating stimulus and analyzed licking behavior to assess learning progress (Fig. 1). The animals were headfixed on a spherical treadmill in front of a computer monitor, on which we presented a drifting grating behind a stationary aperture. The gratings varied along 2 orthogonal orientations and 6 levels of contrast and were presented in a random order. The presentation of one orientation was immediately followed by a fluid reward; the other orientation had no consequences (Fig. $1 A, B)$. We measured licks as an indicator of learning progress, and observed pronounced changes in licking behavior across training sessions. Consider, for example, the sequence of training sessions shown in Figure $1 C-E$. In the "naive" stage, the animal licked spontaneously, but licking was unrelated to the visual stimulus (Fig. 1C). In the "intermediate" stage, the animal licked more frequently during the stimulus presentation, yet the number of licks was similar for the rewarded and unrewarded orientation (Fig. 1D). In this stage, the animal likely has associated the occurrence of either stimulus with the delivery of a reward. Finally, in the "trained" stage, the animal showed anticipatory licks during the rewarded orientation, and largely suppressed licks during the unrewarded orientation (Fig. 1E). In this stage, the animal has learned about the significance of the stimulus' orientation.

We analyzed licking behavior of individual animals across learning stages and found that orientation discrimination learning can be decomposed into a sequence of distinct stages (Fig. 2). To quantify licking behavior, we computed, for each stimulus separately, the cumulative sum of an LI, defined as the difference in lick rates between the final second during and the final second before stimulus presentation (Fig. 1E, black horizontal bars), divided by their sum. Changes in the slope of this cumulative sum indicate changes in the animals' behavior. We illustrate the sequence of distinct learning stages in 3 example mice (Fig. 2A-C). During the naive stage, cumulative LIs for the rewarded (blue) stimulus and unrewarded (red) stimulus fluctuate around zero. During the intermediate stage, the cumulative LIs rise with similar slopes because the animals increased lick rates after stimulus onset, regardless of its orientation. During the trained stage, the cumulative LIs finally diverge because the animals increase further anticipatory licking for the rewarded orientation and/or suppress it for the unrewarded orientation. This point of divergence can best be seen as a change of slope in the difference between the 
cumulative LIs (Fig. 2F-H). We used change point analyses (Gallistel et al., 2001) to find significant changes in slope and identify transitions between learning stages. We defined the transition from the naive to the intermediate stage as the first change point in the cumulative LI for the rewarded stimulus (Fig. $2 A-C$, earliest blue circles). Analogously, we defined the transition from the intermediate to the trained stage as the first change point in the difference of the two cumulative LIs (Fig. $2 F-H$, earliest black circles). Relying on the very first change points is a conservative strategy and avoids contamination by trials from the subsequent stage. To quantify how distinct these transitions were, we determined how many change points were needed to reach $80 \%$ of the terminal slope, estimated from the final half of the trials.

All 3 example animals reached this criterion, in the cumulative LIs and in their difference, with only one or two changes in slope. These data indicate that there were few but clear-cut changes in behavior; before and after these changes, behavior was largely constant for a stretch of trials.

This distinct sequence of learning stages was representative for the entire sample of animals (Fig. 2D,I). For cumulative LIs to the rewarded orientation, all animals showed only one or two change points, after which performance reached the terminal slope (Fig. 2D). Similarly, for the difference in cumulative LIs, all animals reaching the trained stage required at most two changes in slope (Fig. 2I).

To further quantify licking behavior and validate the placement of change points, we performed an ideal observer analyses (Fig. 2E,J). We separated trials based on change point locations and quantified how well an ideal observer could decode, from licking behavior, the presence of the stimulus or its orientation. In the naive stage, licking was not predictive of stimulus presence (Fig. 2E; lick rate before vs during the rewarded stimulus, area under the receiver operating characteristic [AUROC]: $0.51 \pm 0.01$, mean, SEM, $n=15$ mice). Stimulus presence, however, could be well decoded from licking behavior during the final two stages $(0.76 \pm 0.02)$. Similarly, during the initial two stages, licking behavior was not predictive of stimulus orientation (Fig. 2J; LIs for rewarded vs unrewarded stimulus, AUROC: $0.50 \pm 0.01, n=10$ mice); in the trained stage, however, stimulus orientation could be well predicted by licking behavior $(0.71 \pm 0.02)$.

Analyzing licking behavior separately for each level of stimulus contrast revealed that mice could detect the stimulus and discriminate its orientation at contrasts as low as $1 \%$, and that stimulus contrast controlled the speed of learning (Fig. 3). In all mice that were trained at multiple contrasts and traversed all
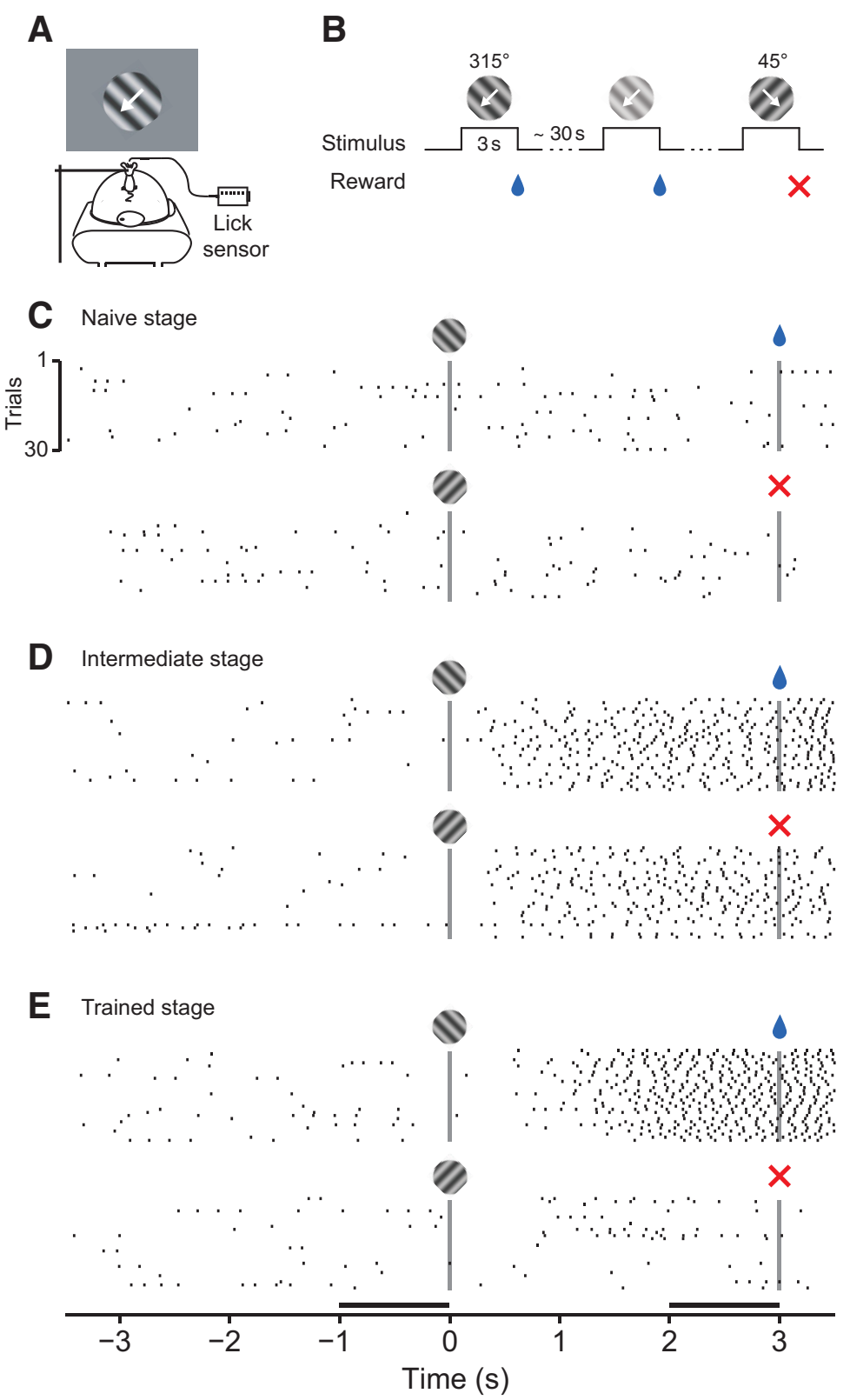

Figure 1. Classical conditioning of orientation discrimination. $A$, Experimental setup. Head-fixed mouse on a spherical treadmill in front of a monitor showing oriented gratings. Reward was delivered through a drinking spout equipped with a lick sensor. $B$, Discrimination learning paradigm. At irregular intervals, one of two oriented gratings was presented at a randomly selected contrast level. White arrow indicates the drift direction of the grating. The presentation of one grating (315 degrees) was immediately followed by a fluid reward; the other grating ( 45 degrees) had no consequences. $\mathbf{C}-\boldsymbol{E}$, Licking behavior of one animal in three example sessions at different learning stages (Mouse M22). Top, Licks to the rewarded stimulus. Bottom, Licks to unrewarded stimulus. Vertical bars represent stimulus onset and offset. $\boldsymbol{E}$, Horizontal bars represent the time windows used to quantify the stimulus. Vertical bars represent sti
streng anticipatory licking.

learning stages $(n=7)$, licking behavior could be used to decode the presence of the stimulus even at $1 \%$ contrast (AUROC: $0.70 \pm 0.04, n=7$; Fig. $3 A-D)$. Compared with the $2 \%$ threshold measured in head-fixed mice pressing a lever (Histed et al., 2012), our value is similar or potentially even better, as active behavior, such as running on a treadmill, can further improve detection performance (Bennett et al., 2013). Furthermore, for the majority of mice, licking behavior reliably indicated, even at $1 \%$ contrast, stimulus orientation $(0.62 \pm 0.04, n=7$; Fig. $3 F-I)$. To examine how contrast affected the speed of learning, we extracted the first change point at each contrast level and ranked them based on 
A Mouse 1
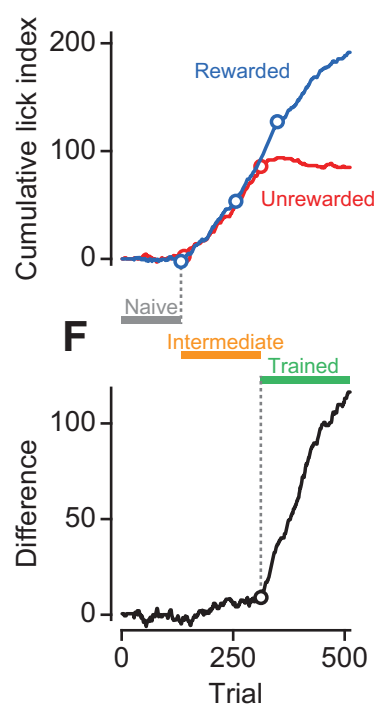

B
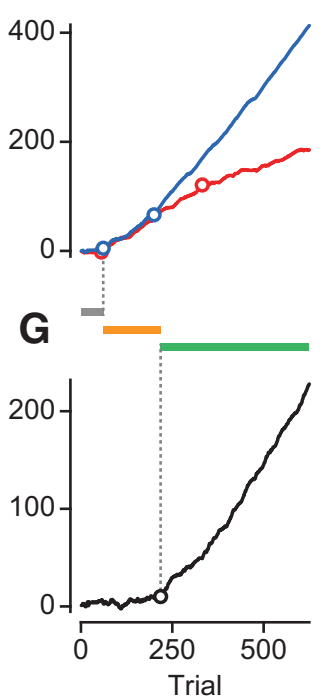

C Mouse 3

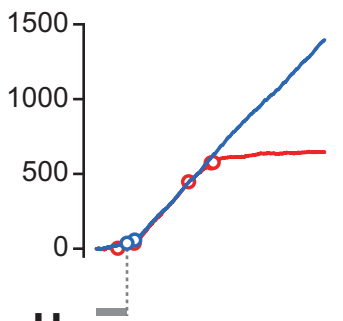

H

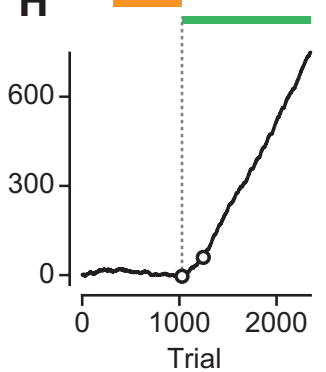

D

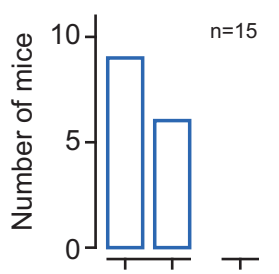

I

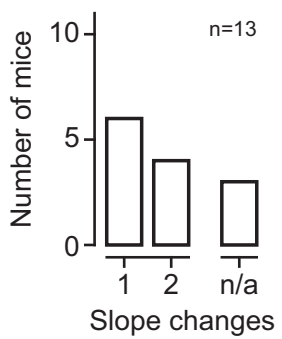

E Area under ROC curve

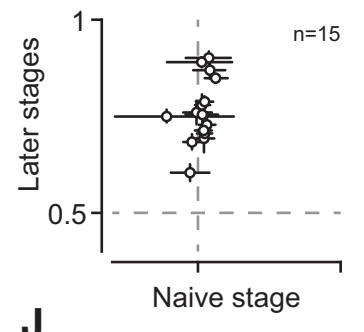

J

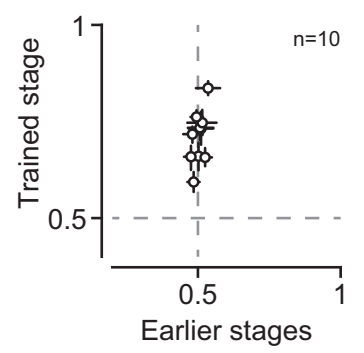

Figure 2. Orientation discrimination learning is characterized by a sequence of distinct stages. A-C, Cumulative Lls across trials to the rewarded (blue) and the unrewarded (red) stimulus for 3 example mice (M22, M28, M42). Circles indicate significant change points. C, The second to last slope change for the unrewarded stimulus is concealed by the large number of trials but becomes evident in the difference $(\boldsymbol{H})$. D, Distribution of the number of change points for the rewarded stimulus across mice $(n=15)$. $\boldsymbol{E}$, Ideal-observer analysis decoding stimulus presence from lick rates in naive versus later (intermediate and trained) stages. $\boldsymbol{F}-\boldsymbol{H}$, Same as $\boldsymbol{A}-\boldsymbol{C}$, difference in cumulative LIs for rewarded and unrewarded orientations. $\boldsymbol{I}$, Same as $\boldsymbol{D}$, for the difference in cumulative $L \mathbf{l}$ s across mice. $n / a$, Number of animals that failed to learn.J, Ideal-observer analysis decoding stimulus orientation from Lls in early (naive and intermediate) versus trained stages. Data points indicate individual mice. Error bars indicate $95 \% \mathrm{Cls}$.

A

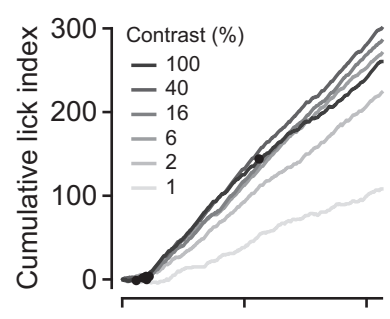

F

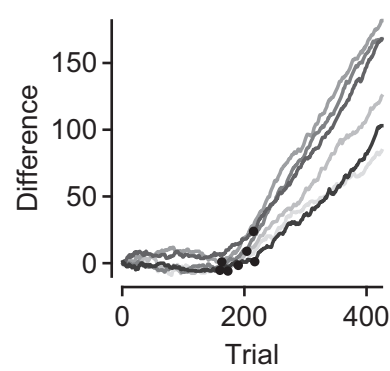

B

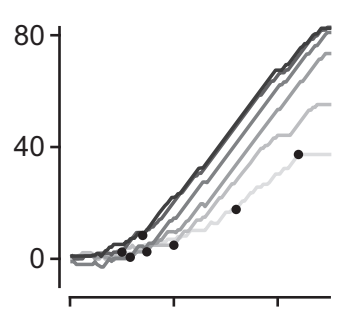

G

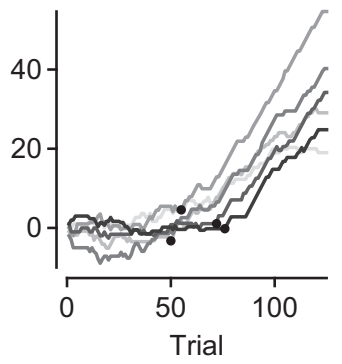

C

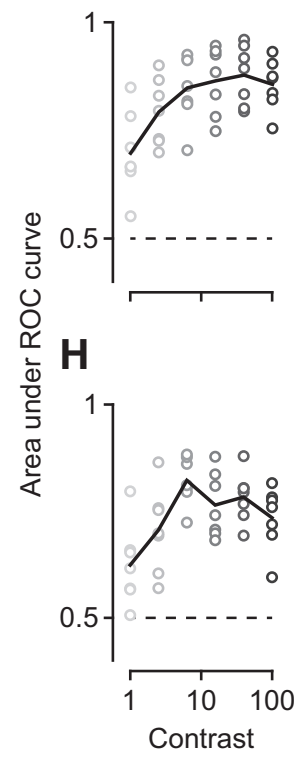

D

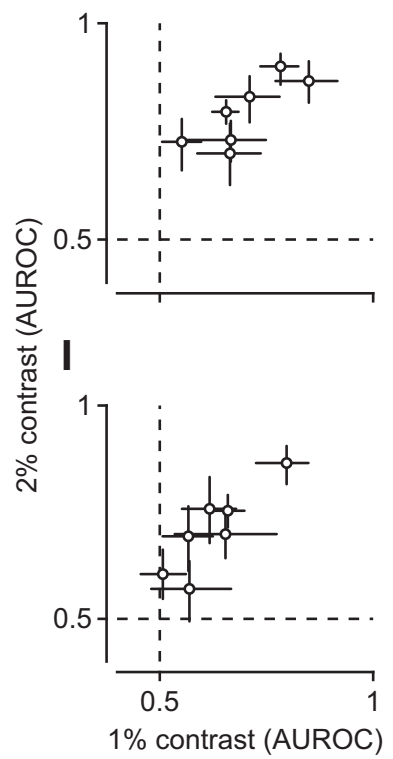

E

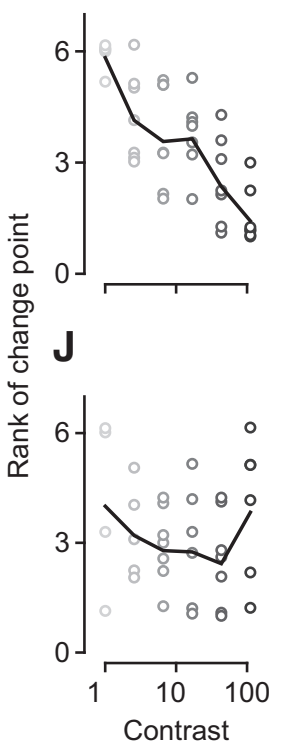

Figure 3. Orientation discrimination performance at different levels of stimulus contrast. $\boldsymbol{A}, \boldsymbol{B}$, Cumulative LIs in response to the rewarded stimulus at different contrast levels for 2 example mice (M110, M42). Black dots indicate significant change points. C, Area under the ROC curve as a function of stimulus contrast. At each contrast level, stimulus presence is decoded from lick rates in the intermediate and trained stage. Circles represent individual animals. Black line indicates the mean across animals. $\boldsymbol{D}$, Same analysis as in $\boldsymbol{C}$, but showing contrast levels of $1 \%$ versus $2 \%$ only. Error bars indicate $95 \%$ Cls. $\boldsymbol{E}$, Rank of the first change point in the cumulative Lls as a function of stimulus contrast. Black line indicates the mean rank across animals. $\boldsymbol{F}, \boldsymbol{G}$, Same as $\boldsymbol{A}, \boldsymbol{B}$, but for difference in cumulative LIs to rewarded and unrewarded stimuli. $\boldsymbol{H}$, Same as $\boldsymbol{C}$, decoding stimulus orientation from Lls in the trained stage. I, Same as $\boldsymbol{D}$, for data in $\boldsymbol{H}$. $\boldsymbol{J}$, Same as $\boldsymbol{E}$, for change points extracted from the difference in LIs. $N=7$ mice.

when they occurred; the later the change point, the higher the rank. The transition from naive to intermediate, where the animals merely had to detect the presence of a stimulus, typically occurred faster with high-contrast stimuli (Fig. $3 E$ ): Data points at $1 \%$ contrast cluster around 6 , indicating that LIs at $1 \%$ contrast are last to change their slope. The transition from intermediate to trained, however, where the animals had to discriminate orientation, tended to occur faster for stimuli of intermediate contrasts (Fig. $3 J$ ). In mice, improved visual performance at intermediate levels of stimulus contrasts has been reported earlier (Long et al., 2015). One potential explanation could be that our relatively large stimulus, at high levels of contrast, engages suppressive mechanisms outside the 

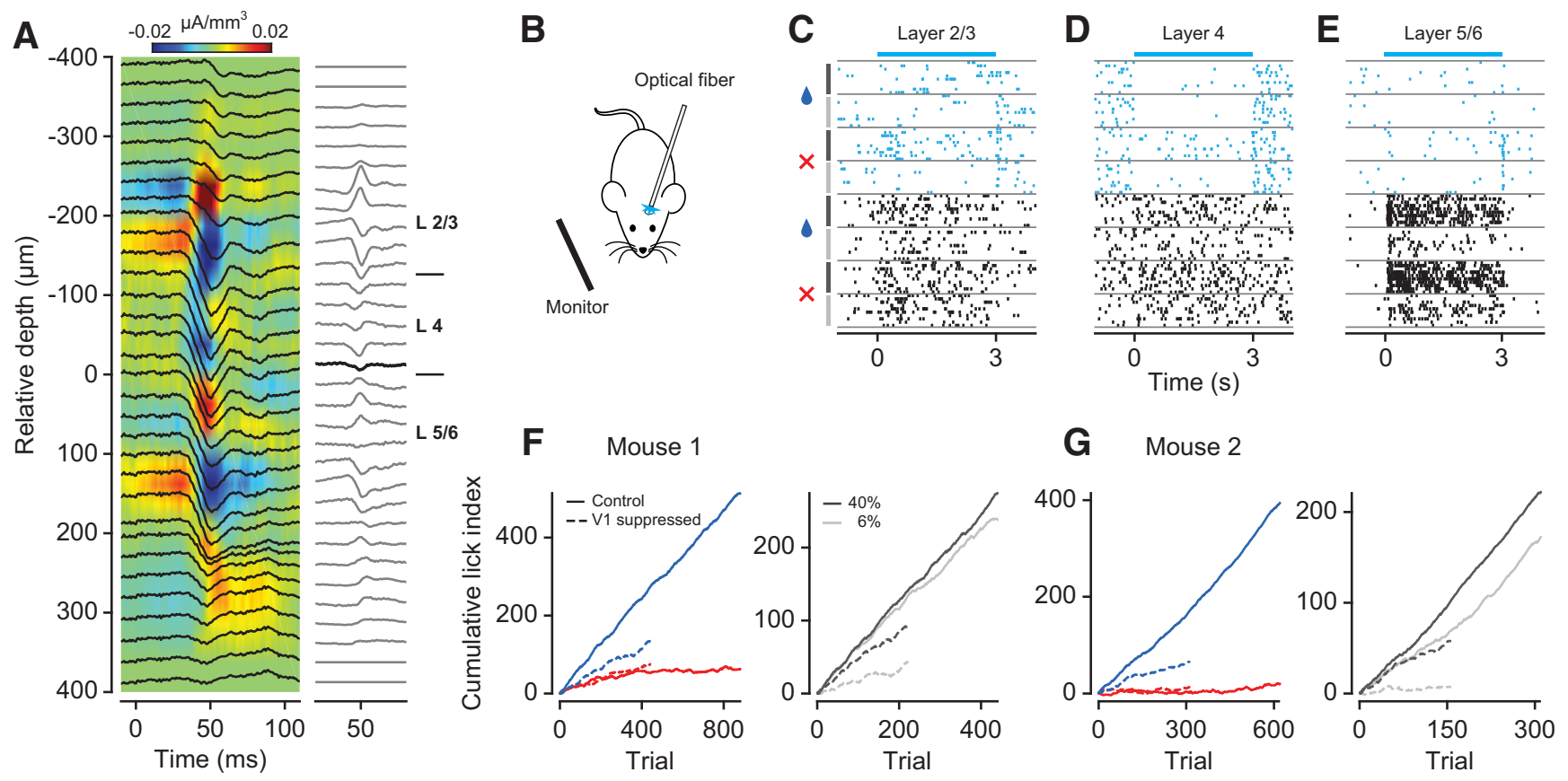

Figure 4. Transient optogenetic suppression of V1 neurons impairs behavioral performance. $A$, Left, LFP (black traces) superimposed on the CSD profile. Right, CSD traces. Bold line indicates the base of layer 4. $\boldsymbol{B}, \mathrm{V} 1$ activity was suppressed by unilateral photo-simulation of $\mathrm{PV}^{+}$inhibitory interneurons expressing ChR2. $C-E$, Raster plots of three example neurons from different $\mathrm{V} 1$ layers (units M120-33-8, -28, -47). Cyan represents V1 suppression by $\mathrm{PV}^{+}$photo-activation. Black represents control condition. Stimulus conditions are separated by gray horizontal lines. Symbols and vertical lines on the left indicate stimulus orientation (blue drop represents rewarded; red cross represents unrewarded) and contrast (black represents 40\%; gray represents 6\%). F, Cumulative Lls for one mouse (M117). Left, Behavioral performance for rewarded (dark blue) versus unrewarded (red) orientation during V1 suppression (dashed lines) and in control condition (solid lines). Right, Rewarded orientation only, at 40\% (black) and 6\% (gray) contrast. G, Same as $\boldsymbol{F}$, for Mouse M199.

classical RF (e.g., Sceniak et al., 1999; Webb et al., 2005), which might impair decoding of stimulus orientation.

Based on these analyses of behavior, we conclude that orientation discrimination learning under classical conditioning is best described as a sequence of distinct stages, where transitions between stages are clear-cut and performance within stages largely constant. We next tested the hypothesis that traversing through these well-defined stages of learning was paralleled by changes in sensory processing in primary visual cortex.

Before studying how such distinct learning stages are reflected in cortical sensory representations, we confirmed that orientation discrimination in a classical conditioning paradigm requires $\mathrm{V} 1$. We found that discriminating grating orientation relies on V1 activity because transient optogenetic suppression of V1 neurons impairs behavior (Fig. 4). We expressed ChR2 in $\mathrm{PV}^{+}$inhibitory interneurons, which we then stimulated with blue light to transiently reduce responses of V1 neurons. We performed CSD analysis (Mitzdorf, 1985) on the LFPs to estimate the base of layer 4, and assigned neurons to putative supragranular (L2/L3), granular (L4), and infragranular layers (L5/L6) (Fig. 4A). We photo-stimulated $\mathrm{PV}^{+}$neurons, in a subset of randomly interleaved trials, during presentation of the stimuli at $40 \%$ or $6 \%$ contrast and observed profound reductions in responsiveness across the depth of cortex (Fig. 4C-E). These reductions were stronger for stimuli at $6 \%$ contrast (mean suppression of $64 \pm 4.7 \%$ ) than for those at $40 \%$ contrast $(52 \pm 4.9 \%, p=$ 0.0006 , paired $t$ test; $n=84$ neurons). When reducing the responsiveness of V1 neurons, anticipatory licking during the rewardpredicting stimulus was much weaker (Fig. $4 F, G$, left, dashed blue line) compared with the control condition without photostimulation (solid blue line). Photo-stimulation did not seem to affect suppression of licking during the unrewarded stimulus (red lines), indicating that the light by itself does not lead to spurious or indifferent licking behavior. These effects of photostimulation not only were specific for the rewarded stimulus, but also depended on its contrast (Fig. 4F, G, right). A constant intensity of photo-stimulation decreased anticipatory licking during the rewarded stimulus when presented at high contrast (black solid vs dashed line) yet nearly abolished it when presented at low contrast (gray solid vs dashed line). These findings show that our transient reduction of $\mathrm{V} 1$ activity interferes with the sensory processing of the stimulus, and does not simply cause random behavior in a disoriented mouse. These findings are consistent with previous work showing that mouse $\mathrm{V} 1$ is required for orientation discrimination (Glickfeld et al., 2013; Poort et al., 2015); we conclude that orientation discrimination under classical conditioning also relies on activity in $\mathrm{V} 1$.

\section{Learning shapes $\mathrm{V} 1$ responses well before the animals discriminate the stimuli}

Having established that orientation discrimination in our classical conditioning paradigm relies on activity in V1, we recorded, during conditioning sessions, extracellular activity from ensembles of individual V1 neurons simultaneously across the depth of cortex. Within individual recording sessions, we interleaved conditioning experiments (the "task"), with measurements of orientation tuning curves outside the context of this task.

To our surprise, we found that V1 neurons showed improved discriminability for the behaviorally relevant orientations already in the intermediate stage, where the animals still did not discriminate the stimuli (Fig. 5). To quantify how well individual neurons could discriminate between the rewarded and unrewarded orientation (the "relevant orientations"), we computed $d$ ', defined as the difference in mean firing rates relative to the pooled $\mathrm{SD}$. The value of $d^{\prime}$ depends on the preferred orientation of a 
A

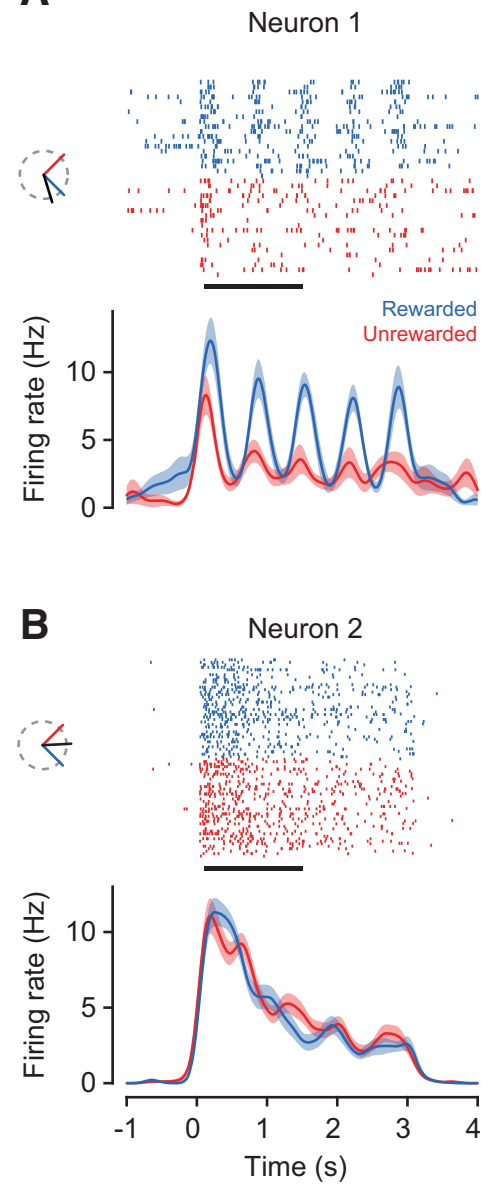

C

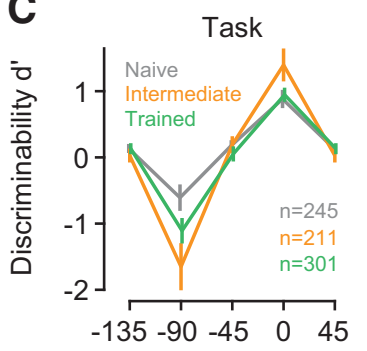

Relative preferred orientation

F

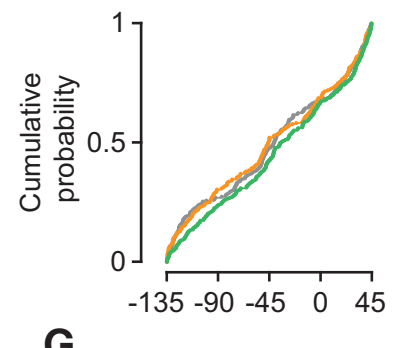

G

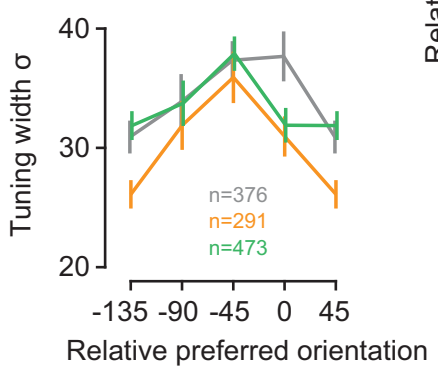

D

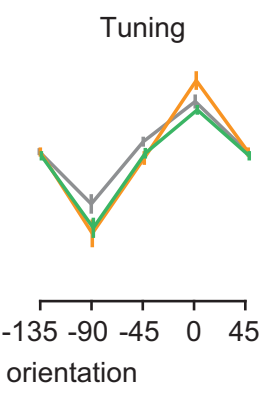

H

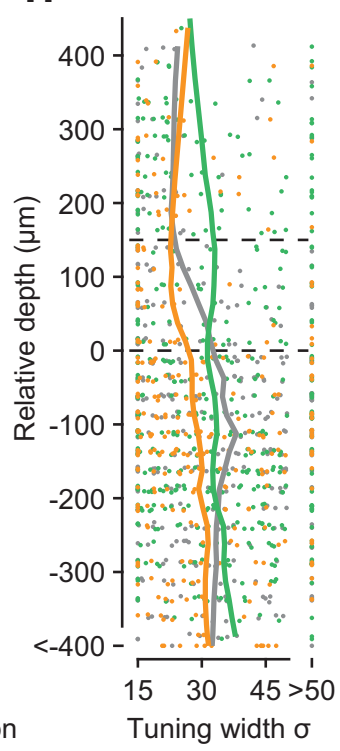

E

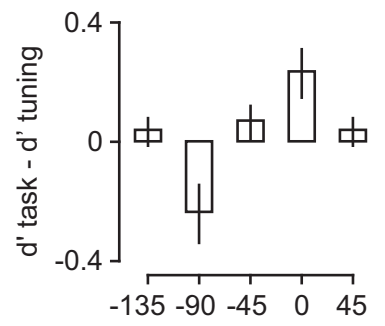

Relative preferred orientation

I

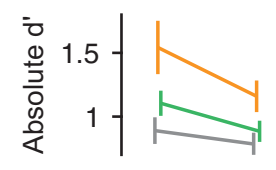

J
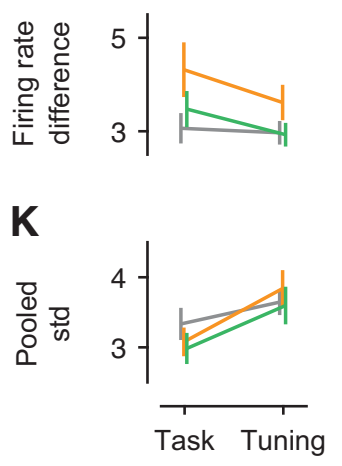

Figure 5. V1 neurons show improved discriminability and sharper orientation tuning already in the intermediate learning stage. $\boldsymbol{A}, \boldsymbol{B}$, Spike rasters and density functions in response to the rewarded (blue) and unrewarded (red) stimulus for two example neurons (units M22-14-16, M81-3-31). Insets, Preferred (black), rewarded (blue), and unrewarded (red) orientations. C, Neural discriminability ( $d^{\prime}$ ) during task performance in the naive (gray), intermediate (orange), and trained stage (green). Bins represent preferred orientation relative to the rewarded orientation. $\boldsymbol{D}, d^{\prime}$ values computed from responses to the same stimuli during orientation tuning measurements. $E$, Mean pairwise differences in $d^{\prime}$ between task and tuning measurements across orientation bins. $\boldsymbol{F}$, Cumulative distribution of relative orientation preferences across learning stages. $\boldsymbol{G}$, Learning-related changes in tuning width as a function of orientation preference relative to the rewarded orientation, for all neurons recorded during the naive, intermediate, and trained stage. $\boldsymbol{H}$, Tuning width $(\sigma)$ and laminar location for neurons in $\boldsymbol{G}$. Trends (vertical lines) were computed with locally weighted, robust regression (lowess). $I$, Absolute $d^{\prime}$ values during task performance versus measurements of orientation tuning, separately for each learning stage. Included are only neurons from bins centered on 0 degrees or -90 degrees in $\boldsymbol{C}$. J, Same for differences in firing rates between rewarded and unrewarded stimuli. $\boldsymbol{K}$, Same for pooled SD; $n=11$ mice; numbers of neurons per learning stage are given in $C$. Error bars indicate \pm 1 SEM.

neuron: A neuron with preferred orientation close to the rewarded orientation, such as the example in Figure $5 A$, should have a positive $d^{\prime}$; neurons whose preferred orientation is somewhat in between, such as the example in Figure $5 B$, receive comparable drive from both orientations and their $d^{\prime}$ should be close to 0 . To compute $d^{\prime}$, we focused on a response time window from 0.1 to $1.5 \mathrm{~s}$ after stimulus onset (Fig. $5 A, B$, black horizontal bar), where anticipatory licking behavior was largely similar between the two orientations (see Fig. 1).

We first examined $\mathrm{V} 1$ responses during task performance and found that the improvements in discriminability were largely restricted to neurons with preferred orientations close to either of the relevant stimulus orientations (Fig. 5C). Binning neurons by their preferred orientation relative to the rewarded orientation revealed that learning improved $d^{\prime}$ values in the two bins centered on relative preferences of 0 (rewarded orientation) and -90 (unrewarded orientation; interaction between learning stage and orientation bin, $p=0.0014$, ANOVA). Follow-up analyses confirmed that, for the neurons with relevant orientation preference, absolute $d^{\prime}$ values at the intermediate stage were higher com- pared with the naive stage ( $p=0.0068$, Tukey's HSD test) and tended to be higher than during trained stage ( $p=0.061$, Tukey's HSD test). We tested whether this selective improvement of $d^{\prime}$ values would depend on laminar location but found no evidence (interaction between learning stage, orientation bin, and layer, $p=0.76$, ANOVA, data not shown).

To test whether improvements in neural discriminability require engagement in the task, we examined responses during measurements of orientation tuning; although we found improvements outside the context of the task, they were weaker than during task performance (Fig. $5 D, E$ ). To evaluate neural discriminability without the animals being engaged in the task, we determined $d^{\prime}$ values from responses during measurements of orientation tuning and also found significant improvements in $d^{\prime}$ with learning. Indeed, the improvements during measurements of orientation tuning depended in the same way on the relative orientation preference of the neurons (Fig. $5 D$; interaction between learning stage and orientation bin, $p=0.036$, ANOVA). Although learning improved discriminability outside the task, $d^{\prime}$ values during orientation tuning were not as pronounced as dur- 
ing task performance (interaction between orientation bin and task, $p=$ 0.0055). These additional improvements in discriminability during the task can best be seen by computing, separately for each neuron, the difference in $d^{\prime}$ values between task and tuning measurements (Fig. 5E). During the task, the mean difference in $d^{\prime}$ values is positive for neurons preferring the rewarded stimulus ( 0 degrees, $p=0.01$, one-sided $t$ test), negative for neurons preferring the unrewarded stimulus ( -90 degrees, $p=0.004)$, and indistinguishable from zero for all other neurons.

Because the improvements in discriminability persisted outside the task, we analyzed the orientation tuning measurements to identify underlying neural mechanisms. The fraction of V1 neurons preferring either the rewarded or unrewarded stimulus was similar overall (main effect of bin: $p=0.25$, log-linear analysis) and remained similar across learning stages (interaction between bin and learning stage: $p=0.79$; data not shown). We also compared, without binning, the distributions of orientation preferences across learning stages and found them to be indistinguishable (Fig. $5 F ; p=0.56$, Anderson-Darling test). These results indicate that classical conditioning of orientation discrimination does not induce any systematic shift in the distributions of orientation preferences.

While the distributions of orientation preferences did not show systematic shifts with learning, we found substantial sharpening of orientation selectivity, which was strong already in the intermediate learning stage (Fig. 5G,H). Consistent with previous reports (Niell and Stryker, 2008; Sun et al., 2016), average tuning width had a clear laminar profile during the naive stage: it was narrower in L2/L3 than in L4 and L5/L6 (Fig. $5 \mathrm{H}$; means of 24 vs 30 vs 37 degrees, main effect of layer, $p<10^{-4}$, ANOVA). Tuning width in these deeper layers, however, sharpened in the intermediate stage (orange, interaction between layer and learning stage: $p=0.038$, ANOVA; intermediate vs naive in L5/L6: $p=$ 0.0035 , Tukey's HSD test). In the trained stage (green), tuning width was generally broad and did not vary across layers (main effect of layer: $p=0.50$, ANOVA). Unlike the improvements in discriminability, the sharpening of orientation tuning width in the intermediate stage did not depend on a neuron's orientation preference but occurred globally across the entire population (interaction between learning stage and orientation bin: $p=0.33$; Fig. 5G). Together, these results indicate that the learning-related improvements seen outside the task were largely mediated by a sharpening of tuning width, which was most pronounced in the intermediate stage.

Given the additional benefit of task engagement, we sought to identify the properties of the neural response that further improved discriminability during the task. We focused on those neurons that showed learning-related improvements (Fig. $5 C$; relative orientation preference bins at 0 and -90 degrees) and examined how absolute $d^{\prime}$ changed between tuning measurements and task performance. As implied by the analyses of pairwise differences (Fig. $5 E$ ), $d^{\prime}$ values were higher during the task than during tuning measurements (Fig.
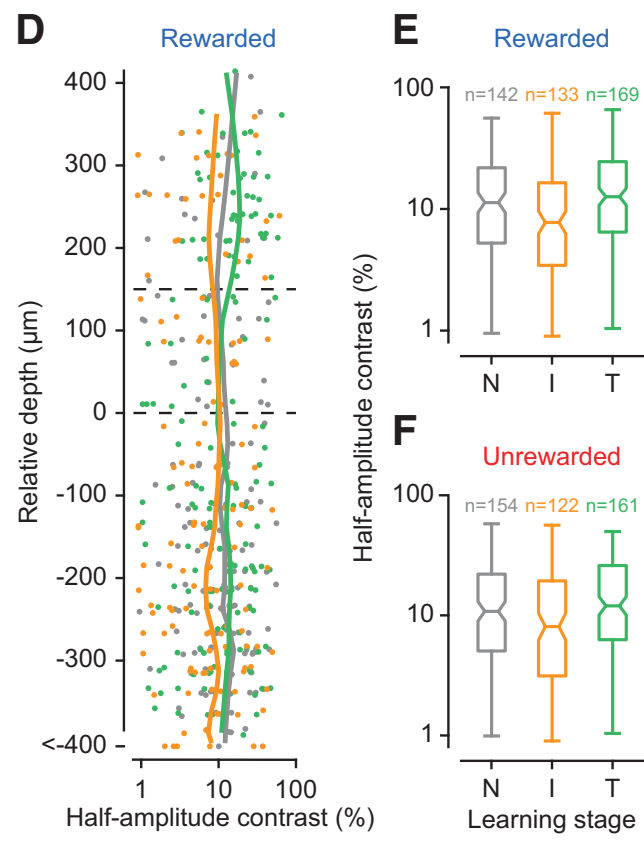

Figure 6. Contrast sensitivity in the population of V1 neurons. $\boldsymbol{A}-\boldsymbol{C}$, Contrast responses of three example V1 neurons (units M110-30-5, M22-14-46, M154-6-15) for the rewarded (blue) and unrewarded (red) stimulus. Because the two stimuli are not the range. $\boldsymbol{F}$, Same for unrewarded stimulus. $N=11$ mice. Conventions as in Figure 5.

5I; main effect of task: $p<10^{-4}$, ANOVA); yet this task-related increase did not seem to depend on learning stage (interaction between task and learning stage: $p=0.11$ ). We decomposed $d^{\prime}$ into differences in firing rates (rewarded-unrewarded; Fig. 5J) and pooled SD (Fig. $5 K$ ). Performing the task increased differences in firing rates (main effect of task: $p=0.0047$ ) and strongly reduced firing rate variability (main effect of task: $p<10^{-4}$ ), neither of them depended on learning stage (interaction between task and learning stage, for both comparisons $p>0.26$ ). Because these task-related improvements were present at all learning stages, they likely result from different levels of engagement. During tuning measurements, the animals passively view a sequence of oriented gratings; during the task, they learn to focus on visual information to anticipate reward. These analyses indicate that being engaged in a perceptual task, as simple as learning to anticipate reward, can improve the reliability of sensory responses in V1.

We finally asked whether progress in orientation discrimination would affect processing of stimulus features other than orientation; to address this question, we examined responses of $\mathrm{V} 1$ neurons to different levels of stimulus contrast (Fig. 6). Because our rewarded stimulus and unrewarded stimulus had different orientations, comparing the contrast responses to these two stimuli within individual neurons would be confounded by differences in sensory drive (Fig. $6 A-C)$. We therefore compared contrast sensitivity in the population of V1 neurons, measured with the same stimulus, across the different learning stages. We fitted contrast responses with a hyperbolic ration function (Albrecht and Hamilton, 1982) and took as a measure of contrast sensitivity the contrast at half the maximum response (Fig. 6A, dotted lines).

We examined responses to the rewarded stimulus and found that contrast sensitivities were highest, across the depth of cortex, in the intermediate stage (Fig. 6D). Pooling neurons across layers, 


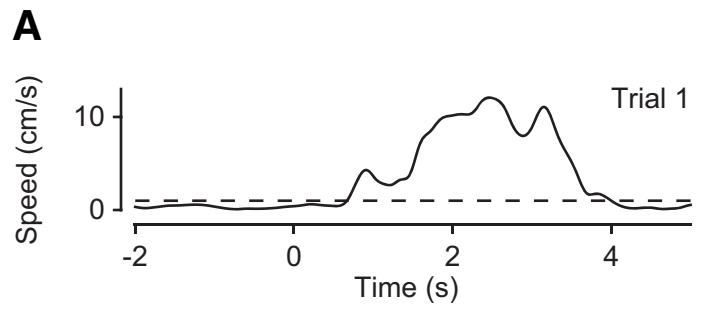

B

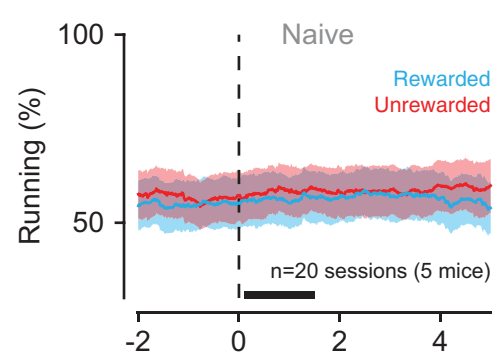

F

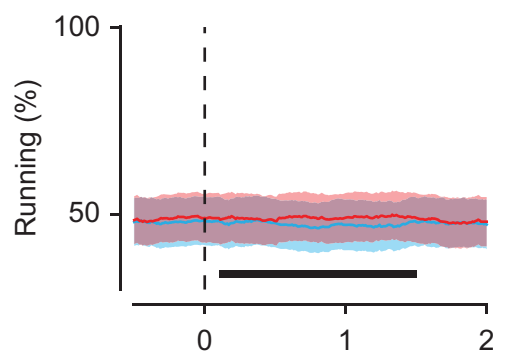

C

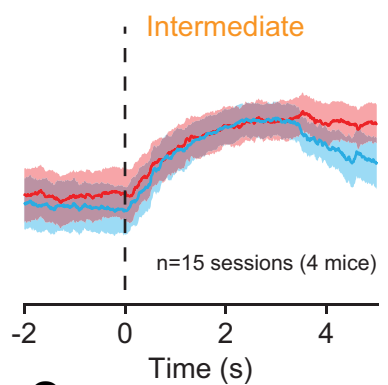

G

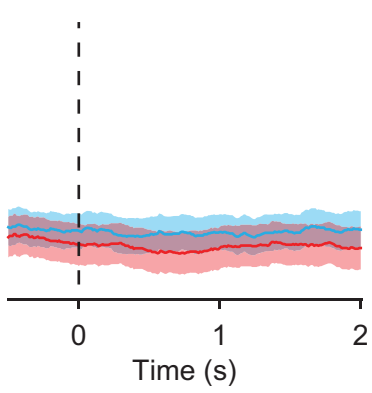

Trial 2

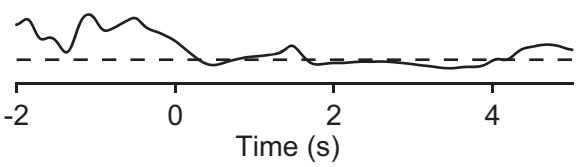


A

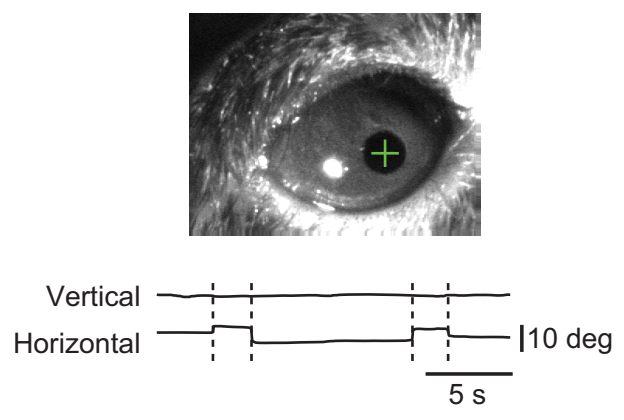

B

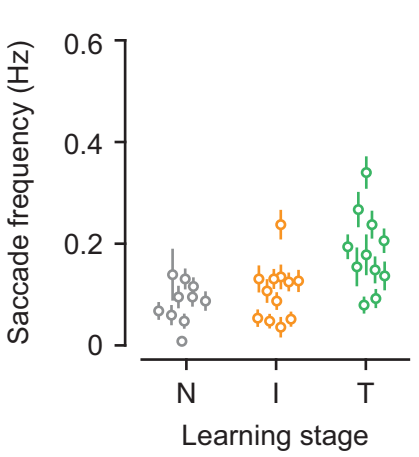

C

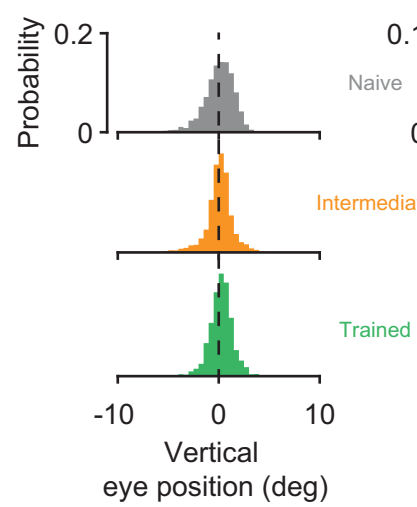

D

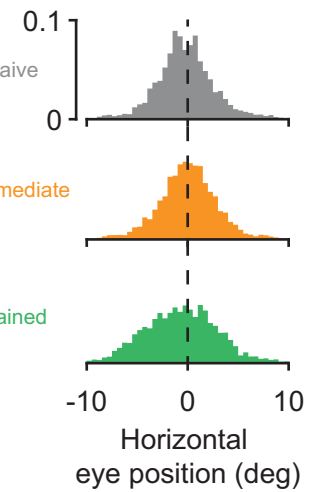

Figure 8. Learning-related changes in V1 processing are not an artifact of eye movements. $\boldsymbol{A}$, Eye position was measured by tracking the pupil under infrared illumination. Top, Example image acquired by the eye-tracking camera. White spot indicates the cornea reflection of the infrared LED. Green cross represents the estimate of the pupil center. Bottom, Example traces for vertical and horizontal eye position. Dashed lines indicate saccades. B, Saccade frequency within $0.1-1.5 \mathrm{~s}$ after stimulus onset across learning stages. Data points indicate recording sessions. Error bars indicate \pm 1 SEM. $C$, Distributions of vertical eye position. $\boldsymbol{D}$, Distributions of horizontal eye position.

et al., 2013; Polack et al., 2013; Erisken et al., 2014; Fu et al., 2014; Lee et al., 2014) and reduce trial-to-trial variability of membrane potential fluctuations (Bennett et al., 2013), it could, in principle, also bring about higher values of $d^{\prime}$ (Fig. 5C$E)$. The increases in $d^{\prime}$ we observed, however, were not confounded by differences in locomotion. We analyzed run-speed profiles from single trials (Fig. $7 A$ ) to determine, for each point in time, the percentage of trials during which the animal was running. As the animals learned the task, locomotion locked to the structure of the trial (Fig. $7 B-D$ ). During the window we used to analyze neural responses, however, the percentages of trials the animals spent running remained largely constant. Only in the trained stage, animals ran more in response to the rewarded than the unrewarded stimulus (Fig. $7 E$; interaction between learning stage and reward: $p<10^{-4}$; ANOVA). Furthermore, $d^{\prime}$ values increased even outside the context of the task, where running behavior remained indistinguishable across the entire trial duration and all learning stages (Fig. 7F-I; main effect of stage: $p=$ 0.48 , ANOVA). Similarly, we observed a narrowing of tuning width with learning outside the context of the task (Fig. $5 G$ ), where locomotion was identical across learning stages. Furthermore, based on previous findings (Erisken et al., 2014; Lee et al., 2014), locomotion should not alter contrast sensitivity. We tested this directly by analyzing data obtained from a separate batch of naive mice, unrelated to the current study. We compared contrast responses between locomotion and stationary trials and found that locomotion increased the maximum response (Fig. 7J; $p=0.0003$, paired $t$ test) without affecting contrast sensitivity (Fig. $7 K ; p=0.20$ ). Together, these results argue against the possibility that the learning-related improvements in V1 sensory processing can be explained by the animals' running behavior.

These learning-related changes in visual processing also cannot be explained by artifacts of eye movements (Fig. 8). We did observe occasional eye movements, which mainly occurred along the horizontal axis. Their overall frequency, however, was very low (naive stage: $0.075 \pm 0.04 \mathrm{~Hz}$; intermediate stage: $0.096 \pm$
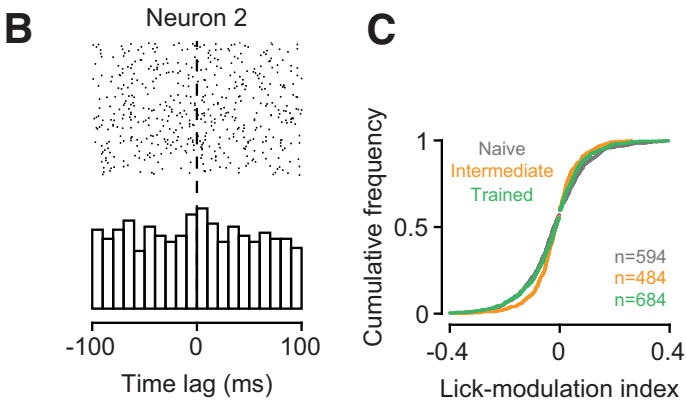

Figure 9. Learning-related changes in V1 processing are not an artifact of licking behavior. $\boldsymbol{A}, \boldsymbol{B}$, Examples of perievent spike (M53-1-8, M117-22-21). C, Cumulative distributions of lick-modulation indices across the population of neurons during the naive (gray), intermediate (orange), and trained stage (green).

$0.05 \mathrm{~Hz}$; trained stage: $0.16 \pm 0.07)$. Although mean saccade frequency changed with learning stage (main effect of stage, $p=$ 0.0021, ANOVA), it was indistinguishable between the naive and intermediate stage ( $p=0.63$, Tukey's HSD test), where learning already shaped V1 responses. In addition, across learning stages, the distributions of eye positions were highly overlapping and centered on a default position.

The learning-related changes in V1 sensory processing also cannot be explained by licking artifacts (Fig. 9). First, we observed changes in $d^{\prime}$ and tuning width outside the task, where the lick spout was completely removed from the setup. Second, we examined licking behavior during the task and found that it only marginally influenced V1 responses. Within the window used to analyze the neural data, we constructed, for each neuron, perievent spike histograms centered on licks (Fig. 9A,B). We classified neurons as lick-modulated if the mean firing rate during a post-lick period of $100 \mathrm{~ms}$ was outside the $99 \% \mathrm{CI}$ around the mean firing rate in the corresponding pre-lick period. The percentage of lickmodulated neurons was small (naive stage: $4.5 \%$; intermediate stage: $5.6 \%$; trained stage: $4.1 \%$ ) and statistically indistinguishable across learning stages (interaction between learning stage and lick-modulation: $p=0.49$, log-linear analysis). We also computed a lick-modulation index, defined as the difference in mean pre-lick and post-lick firing rates divided by their sum, and compared the distributions of these indices across learning stages (Fig. 9C). An omnibus test showed a significant difference be- 
A

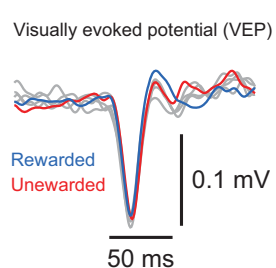

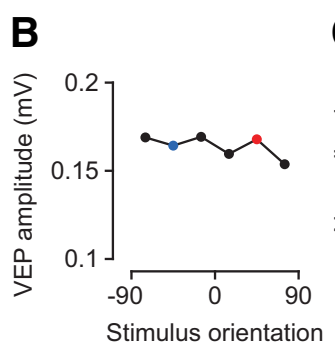

C

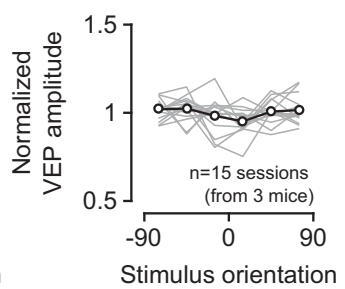

Figure 10. VEPs during measurements of orientation tuning. $\boldsymbol{A}$, VEPs from one recording session in response to gratings of six different orientations (M110-36). VEPs for the rewarded and unrewarded stimulus are shown in blue and red. $\boldsymbol{B}$, Amplitudes of VEPs in $\boldsymbol{A}$. $\boldsymbol{C}$, Normalized VEP amplitude across stimulus orientations for all sessions recorded in the trained stage. Gray lines indicate individual recording sessions, normalized to the mean amplitude across orientations. Black line indicates the mean across sessions.

tween the three distributions ( $p=0.001$, Anderson-Darling test). Follow up-analyses then revealed that the indices were actually less extreme in the intermediate (orange) than in the naive (gray, $p=0.0002$ ) and trained stages (green, $p=0.0061$ ). These results argue against the possibility that the learning-related changes in V1 processing artificially arise from differences in licking behavior.

Finally, we rejected the possibility that the learning-related changes result from a disproportionate exposure to the two orientations presented during the task (Fig. 10). In mouse V1, repeated exposure to a certain orientation can lead to persistent enhancements of the visually evoked response to that stimulus (stimulus-selective response potentiation [SRP]) (Frenkel et al., 2006; Cooke et al., 2015). SRP, however, is typically observed after prolonged presentation of the same stimulus at high levels of contrast (100-400 blocks of stimulus presentation at 100\% contrast) (Frenkel et al., 2006). We do not expect that our paradigm can lead to SRP. Although we did present two orientations only during the task, 4 of our 6 levels of stimulus contrast were below what is required to produce SRP $(>12 \%$ contrast) (Frenkel et al., 2006). At sufficiently high levels of contrast, the two stimuli were presented 10-15 times during the task. Interleaved measurements of orientation tuning involved 20 presentations of a random sequence of gratings (including the rewarded and unrewarded orientation). Although such a protocol is unlikely to result in SRP, we directly tested this possibility by comparing, in trained animals, evoked potentials across orientations. We computed VEP traces, separately for six stimulus orientations, by averaging the stimulus-triggered LFP across electrode channels in layer 4 (Fig. 10A). We determined VEP amplitudes as the trough-to-peak difference and compared them across stimulus orientations (Fig. 10 B,C). Mean VEP amplitudes did not differ across orientations (main effect of stimulus orientation: $p=0.99$, ANOVA), indicating that the learning-related changes are not simply caused by a disproportionate exposure to the rewarded and unrewarded orientation.

\section{Discussion}

We used a classical conditioning paradigm to investigate how learning about the behavioral relevance of stimulus orientation affects sensory processing in mouse V1. Analyzing behavior in individual animals, we found that orientation discrimination learning occurred in a sequence of distinct stages. During an intermediate stage, well before successful discrimination was expressed in the animals' behavior, we observed substantial modulations of V1 activity: improved discriminability, sharper orientation tuning, and higher contrast sensitivity. We propose that, even in a simple learning paradigm, classical conditioning, learn- ing is aided by early modulations of responses in visual cortex, which selectively enhance the representation of those sensory signals that are relevant for behavior.

Improvements in sensory processing have long been known from perceptual learning; there are similarities, but also fundamental differences, between this line of research and our study. Perceptual learning refers to improvements in perceptual performance with extensive practice (but for faster effects, see, e.g., Fahle et al., 1995), typically involving thresholdlevel stimuli (e.g., McKee and Westheimer, 1978; Poggio et al., 1992; Schoups et al., 1995). Our study, in contrast, uses orthogonal stimulus orientations far above discrimination thresholds of the mouse $(<10$ degrees) (Andermann et al., 2010; Glickfeld et al., 2013). In perceptual learning sessions, subjects already know which stimulus feature is relevant to solve the task; in contrast, during initial sessions of our paradigm, the behavioral relevance of grating orientation is to the animal unknown. Rather than investigating neural signatures of perceptual improvements by practice, which can involve thousands of trials (e.g., 150,000 trials) (Yang and Maunsell, 2004), we investigated how sensory processing changes as the behavioral relevance of the visual input becomes clear, which could happen after few trials only (see, e.g., Fig. 2B). Despite these differences in task requirements and training protocols, there are important similarities: First, perceptual learning of orientation discrimination can improve selectivity of V1 neurons (e.g., Schoups et al., 2001; Yang and Maunsell, 2004; Raiguel et al., 2006); these improvements, however, were strongest for neurons optimally suited to the task, which contrasts with the global sharpening of tuning we observed. Second, a fraction of our stimuli had contrasts close to threshold, which might have mediated perceptual learning for stimulus contrast. Third, perceptual learning can affect cortical representations outside the context of the task (e.g., Schoups et al., 2001; Yang and Maunsell, 2004; Raiguel et al., 2006; Hua et al., 2010). Fourth, effects of perceptual learning can depend on the level of engagement (e.g., Crist et al., 2001; Yang and Maunsell, 2004; Polley et al., 2006; Li et al., 2008) or the specificity of a task (Li et al., 2004). These similarities might indicate that the two forms of learning share fundamental mechanisms of cortical plasticity.

Our finding of distinct changes in behavior is consistent with recent analyses of learning curves in individual subjects. Learning has traditionally been understood as a smooth, hill-climbing process, during which performance gradually increases with the number of trials before reaching an asymptotic level. This process is captured by the classic learning curve, often expressed as an inverse exponential function. Such gradually increasing curves, however, might arise from averaging across subjects who, individually, show step-like changes in behavior at different points in time (Gallistel et al., 2004). Indeed, analyses of single-subject data have revealed abrupt changes in a number of learning paradigms, such as autoshaping in pigeons, eye-blink conditioning in rabbits, and proboscis extension in honeybees (Gallistel et al., 2004; Papachristos and Gallistel, 2006; Bazhenov et al., 2013). Similarly abrupt changes are present in several of our mice, suggesting that orientation discrimination learning can follow the same dynamics.

One way to account for abrupt changes in behavior is to explain conditioned responses within the framework of decisionmaking (Gallistel and Gibbon, 2000; Gallistel et al., 2004). In the 
context of learning, the animal accumulates, across trials, the evidence that a particular stimulus makes a difference (i.e., predicts a reward). This evidence-accumulation process is thought operate during the acquisition of the conditioned response. After an internal decision-variable has reached a bound, the animal shows the conditioned response (i.e., has learned). The implication is that behavior can change abruptly, and remain at a constant level afterward, similar to what we observed in some of our animals.

Sudden changes in behavior, however, do not necessarily imply that learning abruptly changes the neural representation of stimuli in visual cortex. It might be that some form of activitydependent plasticity (Caporale and Dan, 2008) leads to a gradual, trial-by-trial strengthening of synaptic connectivity between neurons along the early visual pathway. Such gradually changing stimulus representations might then be fed to downstream areas, which implement threshold-like decision processes (Bazhenov et al., 2013; Latimer et al., 2015) that finally translate into behavior.

Does learning dynamically shift the preferences of individual V1 neurons? If so, we should have seen improved discriminability during task performance but not during tuning measurements, potentially in neurons that were driven equally well by the two stimuli (e.g., those preferring horizontal gratings). Although our data do not suggest any such dynamic shifts of preferences with learning, a decisive answer to this question requires longitudinal tracking of orientation preferences across learning stages. Chronic tracking during discrimination learning has been achieved with two-photon imaging of mouse V1 (Poort et al., 2015). Although orientation tuning was not measured, these data reveal how the relative response to a rewarded versus unrewarded orientation is affected by learning. In this study, learning reduced day-to-day fluctuations in relative response strength of those neurons that already showed a bias before learning. In addition, learning biased responses of previously indiscriminate neurons toward the rewarded stimulus. Learning has long been known to shift tuning preferences in primary auditory cortex, in particular with fear conditioning (Edeline et al., 1993), but also with other paradigms (Weinberger, 2004). Whether learning can induce comparable shifts in visual cortex requires further research.

Our most striking observation is that signatures of learning in V1 were fully expressed well before the behavior indicated that the animals had learned to discriminate the stimuli. The learning effects on V1 responses were at least as strong, sometimes even stronger, in the intermediate than in the trained stage. Such pronounced changes in the spiking responses of V1 neurons early in discrimination learning have not been documented yet. In a number of studies, however, effects of learning have been shown to wax and wane. In primary auditory cortex (A1) of gerbils, synaptic inhibition is reduced with learning progress but returns to pretraining levels when animals become experts (Sarro et al., 2015). Tonotopic representations of sound frequency in rat Al can expand during initial stages of training and later shrink again (Takahashi et al., 2010), consistent with the observation that cortical map plasticity in A1 is a transient phenomenon occurring during the first weeks of training (Reed et al., 2011). CA1 neurons in rat hippocampus show enhanced excitability during initial training but return to pretraining levels with additional practice (Zelcer et al., 2006). Finally, BOLD activity in human V1 increases during learning but relaxes to pretraining levels with additional training while behavioral performance remains high (Yotsumoto et al., 2008).

Part of these early improvements in sensory processing might reflect the presence of a top-down signal, such as attention. We argue that the animals cannot learn this task without attending to the orientation of the stimulus. We speculate that attention is focused in the intermediate stage and enhances those aspects of the visual scene that are behaviorally relevant. Indeed, the effects of learning we measured are reminiscent of well-known effects of attention on neurons in visual cortex: improved selectivity for stimulus features (David et al., 2008; O'Connell et al., 2014) and improved sensitivity for stimulus contrast (Reynolds et al., 2000; Martínez-Trujillo and Treue, 2002; but see Williford and Maunsell, 2006; Pooresmaeili et al., 2010). Attention is indeed a key element in contemporary theories of associative learning (Mackintosh, 1975; Pearce and Hall, 1980; Gottlieb, 2012), and our paradigm might be well suited to reveal attentional effects: low levels of stimulus contrast make anticipation of the consequences difficult, and more difficult tasks typically lead to stronger attentional effects (Chen et al., 2008). Attentional modulation of V1 in human and nonhuman primates has been shown to change with learning (Gilbert et al., 2000; Bartolucci and Smith, 2011), which might explain the absence of further improvements in the trained stage. Attention, however, cannot be the only factor because improvements in discriminability and sharpening of orientation tuning curves occurred even outside the context of the task.

Which neural circuits could shape V1 responses during orientation discrimination learning? The activity of midbrain dopaminergic neurons plays a key role in learning to associate a stimulus with reinforcement. In rodents, however, direct dopaminergic innervation of dorsal thalamus or visual cortex is sparse (Pinaud et al., 2006; García-Cabezass et al., 2009). Any dopaminergic contribution might therefore be indirect, such as via glutamatergic long-range projections originating in prefrontal cortex. Another candidate mechanism is the release of acetylcholine by neurons in the basal forebrain. In V1, acetylcholine can amplify effects of visual attention (Herrero et al., 2008), improve behavioral discrimination performance (Pinto et al., 2013), or render neurons sensitive for the timing of reward (Chubykin et al., 2013). Which of these potential mechanisms might shape V1 sensory processing in the intermediate learning stage is an open question.

In conclusion, these early improvements in sensory processing might reflect a key role of cortex in learning a visually guided task. During discrimination learning, V1 might send a "teaching signal" to subcortical structures, providing information about the visual context during anticipatory licking. Such a role of sensory cortex is a key element in a recent model of oculomotor learning (Fee, 2012), which might provide a general framework applicable to a wider range of learning paradigms. From this perspective, V1 would enhance, already in the intermediate stage, behaviorally relevant sensory information, which is used to learn the mapping between stimuli and outcomes.

\section{References}

Albrecht DG, Hamilton DB (1982) Striate cortex of monkey and cat: contrast response function. J Neurophysiol 48:217-237. Medline

Andermann ML, Kerlin AM, Reid RC (2010) Chronic cellular imaging of mouse visual cortex during operant behavior and passive viewing. Front Cell Neurosci 4:3. CrossRef Medline

Balsam PD, Gallistel CR (2009) Temporal maps and informativeness in associative learning. Trends Neurosci 32:73-78. CrossRef Medline

Bartolucci M, Smith AT (2011) Attentional modulation in visual cortex is modified during perceptual learning. Neuropsychologia 49:3898-3907. CrossRef Medline

Bazhenov M, Huerta R, Smith BH (2013) A computational framework for understanding decision making through integration of basic learning rules. J Neurosci 33:5686-5697. CrossRef Medline

Bennett C, Arroyo S, Hestrin S (2013) Subthreshold mechanisms underlying state-dependent modulation of visual responses. Neuron 80:350-357. CrossRef Medline 
Caporale N, Dan Y (2008) Spike timing-dependent plasticity: a Hebbian learning rule. Annu Rev Neurosci 31:25-46. CrossRef Medline

Chen Y, Martinez-Conde S, Macknik SL, Bereshpolova Y, Swadlow HA, Alonso JM (2008) Task difficulty modulates the activity of specific neuronal populations in primary visual cortex. Nat Neurosci 11:974-982. CrossRef Medline

Chubykin AA, Roach EB, Bear MF, Shuler MG (2013) A cholinergic mechanism for reward timing within primary visual cortex. Neuron 77:723735. CrossRef Medline

Cleveland WS (1979) Robust locally weighted regression and smoothing scatterplots. J Am Stat Assoc 74:829-836. CrossRef

Cooke SF, Bear MF (2010) Visual experience induces long-term potentiation in the primary visual cortex. J Neurosci 30:16304-16313. CrossRef Medline

Cooke SF, Komorowski RW, Kaplan ES, Gavornik JP, Bear MF (2015) Visual recognition memory, manifested as long-term habituation, requires synaptic plasticity in V1. Nat Neurosci 18:262-271. CrossRef Medline

Crist RE, Li W, Gilbert CD (2001) Learning to see: experience and attention in primary visual cortex. Nat Neurosci 4:519-525. CrossRef Medline

David SV, Hayden BY, Mazer JA, Gallant JL (2008) Attention to stimulus features shifts spectral tuning of V4 neurons during natural vision. Neuron 59:509-521. CrossRef Medline

Edeline JM, Pham P, Weinberger NM (1993) Rapid development of learning-induced receptive field plasticity in the auditory cortex. Behav Neurosci 107:539-551. CrossRef Medline

Erisken S, Vaiceliunaite A, Jurjut O, Fiorini M, Katzner S, Busse L (2014) Effects of locomotion extend throughout the mouse early visual system. Curr Biol 24:2899-2907. CrossRef Medline

Fahle M, Edelman S, Poggio T (1995) Fast perceptual learning in hyperacuity. Vision Res 35:3003-3013. CrossRef Medline

Fee MS (2012) Oculomotor learning revisited: a model of reinforcement learning in the basal ganglia incorporating an efference copy of motor actions. Front Neural Circuits 6:38. CrossRef Medline

Frenkel MY, Bear MF (2004) How monocular deprivation shifts ocular dominance in visual cortex of young mice. Neuron 44:917-923. CrossRef Medline

Frenkel MY, Sawtell NB, Diogo AC, Yoon B, Neve RL, Bear MF (2006) Instructive effect of visual experience in mouse visual cortex. Neuron 51:339-349. CrossRef Medline

Fu Y, Tucciarone JM, Espinosa JS, Sheng N, Darcy DP, Nicoll RA, Huang ZJ, Stryker MP (2014) A cortical circuit for gain control by behavioral state. Cell 156:1139-1152. CrossRef Medline

Furmanski CS, Schluppeck D, Engel SA (2004) Learning strengthens the response of primary visual cortex to simple patterns. Curr Biol 14:573578. CrossRef Medline

Gallistel CR, Gibbon J (2000) Time, rate, and conditioning. Psychol Rev 107:289-344. CrossRef Medline

Gallistel CR, Mark TA, King AP, Latham PE (2001) The rat approximates an ideal detector of changes in rates of reward: implications for the law of effect. J Exp Psychol Anim Behav Process 27:354-372. CrossRef Medline

Gallistel CR, Fairhurst S, Balsam P (2004) The learning curve: implications of a quantitative analysis. Proc Natl Acad Sci U S A 101:13124-13131. CrossRef Medline

García-Cabezass MA, Martínez-Sánchez P, Sánchez-González MA, Garzón M, Cavada C (2009) Dopamine innervation in the thalamus: monkey versus rat. Cereb Cortex 19:424-434. CrossRef Medline

Gavornik JP, Bear MF (2014) Higher brain functions served by the lowly rodent primary visual cortex. Learn Mem 21:527-533. CrossRef Medline

Ghose GM, Yang T, Maunsell JH (2002) Physiological correlates of perceptual learning in monkey V1 and V2. J Neurophysiol 87:1867-1888. CrossRef Medline

Gilbert CD, Li W (2012) Adult visual cortical plasticity. Neuron 75:250264. CrossRef Medline

Gilbert CD, Li W (2013) Top-down influences on visual processing. Nat Rev Neurosci 14:350-363. CrossRef Medline

Gilbert C, Ito M, Kapadia M, Westheimer G (2000) Interactions between attention, context and learning in primary visual cortex. Vision Res 40: 1217-1226. CrossRef Medline

Glickfeld LL, Histed MH, Maunsell JH (2013) Mouse primary visual cortex is used to detect both orientation and contrast changes. J Neurosci 33: 19416-19422. CrossRef Medline

Goltstein PM, Coffey EB, Roelfsema PR, Pennartz CM (2013) In vivo twophoton $\mathrm{Ca}^{2+}$ imaging reveals selective reward effects on stimulus-specific assemblies in mouse visual cortex. J Neurosci 33:11540-11555. CrossRef Medline

Gottlieb J (2012) Attention, learning, and the value of information. Neuron 76:281-295. CrossRef Medline

Hazan L, Zugaro M, Buzsáki G (2006) Klusters, NeuroScope, NDManager: a free software suite for neurophysiological data processing and visualization. J Neurosci Methods 155:207-216. CrossRef Medline

Herrero JL, Roberts MJ, Delicato LS, Gieselmann MA, Dayan P, Thiele A (2008) Acetylcholine contributes through muscarinic receptors to attentional modulation in V1. Nature 454:1110-1114. CrossRef Medline

Heumann D, Leuba G, Rabinowicz T (1977) Postnatal development of the mouse cerebral neocortex: II. Quantitative cytoarchitectonics of visual and auditory areas. J Hirnforsch 18:483-500. Medline

Histed MH, Carvalho LA, Maunsell JH (2012) Psychophysical measurement of contrast sensitivity in the behaving mouse. J Neurophysiol 107: 758-765. CrossRef Medline

Hua T, Bao P, Huang CB, Wang Z, Xu J, Zhou Y, Lu ZL (2010) Perceptual learning improves contrast sensitivity of V1 neurons in cats. Curr Biol 20:887-894. CrossRef Medline

Jehee JF, Ling S, Swisher JD, van Bergen RS, Tong F (2012) Perceptual learning selectively refines orientation representations in early visual cortex. J Neurosci 32:16747-16753a. CrossRef Medline

Kreile AK, Bonhoeffer T, Hübener M (2011) Altered visual experience induces instructive changes of orientation preference in mouse visual cortex. J Neurosci 31:13911-13920. CrossRef Medline

Latimer KW, Yates JL, Meister ML, Huk AC, Pillow JW (2015) Neuronal modeling: single-trial spike trains in parietal cortex reveal discrete steps during decision-making. Science 349:184-187. CrossRef Medline

Law CT, Gold JI (2008) Neural correlates of perceptual learning in a sensory-motor, but not a sensory, cortical area. Nat Neurosci 11:505-513. CrossRef Medline

Lee AM, Hoy JL, Bonci A, Wilbrecht L, Stryker MP, Niell CM (2014) Identification of a brainstem circuit regulating visual cortical state in parallel with locomotion. Neuron 83:455-466. CrossRef Medline

Li W, Piëch V, Gilbert CD (2004) Perceptual learning and top-down influences in primary visual cortex. Nat Neurosci 7:651-657. CrossRef Medline

Li W, Piëch V, Gilbert CD (2008) Learning to link visual contours. Neuron 57:442-451. CrossRef Medline

Liu BH, Li P, Sun YJ, Li YT, Zhang LI, Tao HW (2010) Intervening inhibition underlies simple-cell receptive field structure in visual cortex. Nat Neurosci 13:89-96. CrossRef Medline

Logothetis NK, Kayser C, Oeltermann A (2007) In vivo measurement of cortical impedance spectrum in monkeys: implications for signal propagation. Neuron 55:809-823. CrossRef Medline

Long M, Jiang W, Liu D, Yao H (2015) Contrast-dependent orientation discrimination in the mouse. Sci Rep 5:15830. CrossRef Medline

Mackintosh NJ (1975) A theory of attention: variations in the associability of stimuli with reinforcement. Psychol Rev 82:276. CrossRef

Macmillan NA, Creelman CD (2005) Detection theory: a user's guide. Mahwah, NJ: Lawrence Erlbaum.

Martínez-Trujillo J, TreueS (2002) Attentional modulation strength in cortical area MT depends on stimulus contrast. Neuron 35:365-370. CrossRef Medline

Maunsell JH (2015) Neuronal mechanisms of visual attention. Annu Rev Vis Sci 1:373-391. CrossRef Medline

McKee SP, Westheimer G (1978) Improvement in vernier acuity with practice. Percept Psychophys 24:258-262. CrossRef Medline

Mitzdorf U (1985) Current source-density method and application in cat cerebral cortex: investigation of evoked potentials and EEG phenomena. Physiol Rev 65:37-100. Medline

Nicholson C, Freeman JA (1975) Theory of current source-density analysis and determination of conductivity tensor for anuran cerebellum. J Neurophysiol 38:356-368. Medline

Niell CM, Stryker MP (2008) Highly selective receptive fields in mouse visual cortex. J Neurosci 28:7520-7536. CrossRef Medline

Niell CM, Stryker MP (2010) Modulation of visual responses by behavioral state in mouse visual cortex. Neuron 65:472-479. CrossRef Medline

O'Connell MN, Barczak A, Schroeder CE, Lakatos P (2014) Layer specific sharpening of frequency tuning by selective attention in primary auditory cortex. J Neurosci 34:16496-16508. CrossRef Medline

Papachristos EB, Gallistel CR (2006) Autoshaped head poking in the mouse: a quantitative analysis of the learning curve. J Exp Anal Behav 85:293-308. CrossRef Medline 
Pearce JM, Bouton ME (2001) Theories of associative learning in animals. Annu Rev Psychol 52:111-139. CrossRef Medline

Pearce JM, Hall G (1980) A model for Pavlovian learning: variations in the effectiveness of conditioned but not of unconditioned stimuli. Psychol Rev 87:532-552. CrossRef Medline

Pinaud R, Tremere LA, de Weerd P (2006) Plasticity in the visual system: from genes to circuits. New York: Springer.

Pinto L, Goard MJ, Estandian D, Xu M, Kwan AC, Lee SH, Harrison TC, Feng G, Dan Y (2013) Fast modulation of visual perception by basal forebrain cholinergic neurons. Nat Neurosci 16:1857-1863. CrossRef Medline

Poggio T, Fahle M, Edelman S (1992) Fast perceptual learning in visual hyperacuity. Science 256:1018-1021. CrossRef Medline

Polack PO, Friedman J, Golshani P (2013) Cellular mechanisms of brain state-dependent gain modulation in visual cortex. Nat Neurosci 16:13311339. CrossRef Medline

Polley DB, Steinberg EE, Merzenich MM (2006) Perceptual learning directs auditory cortical map reorganization through top-down influences. J Neurosci 26:4970-4982. CrossRef Medline

Pooresmaeili A, Poort J, Thiele A, Roelfsema PR (2010) Separable codes for attention and luminance contrast in the primary visual cortex. J Neurosci 30:12701-12711. CrossRef Medline

Poort J, Khan AG, Pachitariu M, Nemri A, Orsolic I, Krupic J, Bauza M, Sahani M, Keller GB, Mrsic-Flogel TD, Hofer SB (2015) Learning enhances sensory and multiple non-sensory representations in primary visual cortex. Neuron 86:1478-1490. CrossRef Medline

Quiroga RQ, Nadasdy Z, Ben-Shaul Y (2004) Unsupervised spike detection and sorting with wavelets and superparamagnetic clustering. Neural Comput 16:1661-1687. CrossRef Medline

Raiguel S, Vogels R, Mysore SG, Orban GA (2006) Learning to see the difference specifically alters the most informative V4 neurons. J Neurosci 26:6589-6602. CrossRef Medline

Reed A, Riley J, Carraway R, Carrasco A, Perez C, Jakkamsetti V, Kilgard MP (2011) Cortical map plasticity improves learning but is not necessary for improved performance. Neuron 70:121-131. CrossRef Medline

Rescorla RA, Wagner AR (1972) A theory of Pavlovian conditioning: variations in the effectiveness of reinforcement and nonreinforcement. In: Classical conditioning, Vol II: Current research and theory (Black AH, Prokasy WF, eds). New York: Appleton-Century-Crofts.

Reynolds JH, Pasternak T, Desimone R (2000) Attention increases sensitivity of V4 neurons. Neuron 26:703-714. CrossRef Medline

Sakatani T, Isa T (2007) Quantitative analysis of spontaneous saccade-like rapid eye movements in C57BL/6 mice. Neurosci Res 58:324-331. CrossRef Medline

Sarro EC, von Trapp G, Mowery TM, Kotak VC, Sanes DH (2015) Cortical synaptic inhibition declines during auditory learning. J Neurosci 35: 6318-6325. CrossRef Medline

Sceniak MP, Ringach DL, Hawken MJ, Shapley R (1999) Contrast's effect on spatial summation by macaque V1 neurons. Nat Neurosci 2:733-739. CrossRef Medline
Scholz FW, Stephens MA (1987) K-Sample Anderson-Darling Tests. J Am Stat Assoc 82:918-924. CrossRef

Schoups AA, Vogels R, Orban GA (1995) Human perceptual learning in identifying the oblique orientation: retinotopy, orientation specificity and monocularity. J Physiol 483:797-810. CrossRef Medline

Schoups A, Vogels R, Qian N, Orban G (2001) Practising orientation identification improves orientation coding in V1 neurons. Nature 412:549 553. CrossRef Medline

Schroeder CE, Mehta AD, Givre SJ (1998) A spatiotemporal profile of visual system activation revealed by current source density analysis in the awake macaque. Cereb Cortex 8:575-592. CrossRef Medline

Schwartz S, Maquet P, Frith C (2002) Neural correlates of perceptual learning: a functional MRI study of visual texture discrimination. Proc Natl Acad Sci U S A 99:17137-17142. CrossRef Medline

Schwarz C, Hentschke H, Butovas S, Haiss F, Stüttgen MC, Gerdjikov TV, Bergner CG, Waiblinger C (2010) The head-fixed behaving rat: procedures and pitfalls. Somatosens Mot Res 27:131-148. CrossRef Medline

Stahl JS, van Alphen AM, De Zeeuw CI (2000) A comparison of video and magnetic search coil recordings of mouse eye movements. J Neurosci Methods 99:101-110. CrossRef Medline

Sun W, Tan Z, Mensh BD, Ji N (2016) Thalamus provides layer 4 of primary visual cortex with orientation- and direction-tuned inputs. Nat Neurosci 19:308-315. CrossRef Medline

Takahashi H, Funamizu A, Mitsumori Y, Kose H, Kanzaki R (2010) Progressive plasticity of auditory cortex during appetitive operant conditioning. Biosystems 101:37-41. CrossRef Medline

Wallace DJ, Greenberg DS, Sawinski J, Rulla S, Notaro G, Kerr JN (2013) Rats maintain an overhead binocular field at the expense of constant fusion. Nature 498:65-69. CrossRef Medline

Wang Q, Gao E, Burkhalter A (2011) Gateways of ventral and dorsal streams in mouse visual cortex. J Neurosci 31:1905-1918. CrossRef Medline

Webb BS, Dhruv NT, Solomon SG, Tailby C, Lennie P (2005) Early and late mechanisms of surround suppression in striate cortex of macaque. J Neurosci 25:11666-11675. CrossRef Medline

Weinberger NM (2004) Specific long-term memory traces in primary auditory cortex. Nat Rev Neurosci 5:279-290. CrossRef Medline

Williford T, Maunsell JH (2006) Effects of spatial attention on contrast response functions in macaque area V4. J Neurophysiol 96:40-54. CrossRef Medline

Yang T, Maunsell JH (2004) The effect of perceptual learning on neuronal responses in monkey visual area V4. J Neurosci 24:1617-1626. CrossRef Medline

Yotsumoto Y, Watanabe T, Sasaki Y (2008) Different dynamics of performance and brain activation in the time course of perceptual learning. Neuron 57:827-833. CrossRef Medline

Zelcer I, Cohen H, Richter-Levin G, Lebiosn T, Grossberger T, Barkai E (2006) A cellular correlate of learning-induced metaplasticity in the hippocampus. Cereb Cortex 16:460-468. CrossRef Medline 